\title{
Flexible Chemiresistive Nitrogen Oxides Sensors Based on a Nanocomposite of Polypyrrole- Reduced Graphene Oxide Grafted Carboxybenzene Diazonium Salts.
}

\section{Djamil GUETTICHE}

Ecole Militaire Polytechnique

Ahmed MEKKI ( $\square$ mekki_ahmedkarim@yahoo.fr)

Ecole Militaire Polytechnique https://orcid.org/0000-0002-9579-6309

BENMOULOUD Lilia

Ecole Militaire Polytechnique

Tighilt Fatma-zohra

Centre de Recherche en Technologie des Semi-conducteurs pour l'Energetique

Amar BOUDJELLAL

Ecole Militaire Polytechnique

\section{Research Article}

Keywords: NO2 sensing, chemiresistive sensor, Polypyrrole, functionalized reduce graphene oxide, 4carboxybenzene diazonium salt

Posted Date: February 19th, 2021

DOI: https://doi.org/10.21203/rs.3.rs-218668/v1

License: (c) (i) This work is licensed under a Creative Commons Attribution 4.0 International License.

Read Full License

Version of Record: A version of this preprint was published at Journal of Materials Science: Materials in Electronics on March 22nd, 2021. See the published version at https://doi.org/10.1007/s10854-02105721-z. 


\section{Abstract}

Nanocomposites of polypyrrole/reduced graphene oxide (PPy/rGO) and polypyrrole/ functionalized reduced graphene oxide with aryl 4-carboxybenzene diazonium salt (PPy/rGO-aryl-COOH) were prepared through covalent bonding by simple one-step chemical oxidative synthesis. The as-prepared nanocomposites were deposited on BOPET substrate by spin coating to test their chemiresistive sensitivity properties on a homemade modular for online detection of $\left(\mathrm{NO}_{2}\right)$ vapors at ambient temperature. Results showed that PPy/rGO-aryl-COOH forms a homogeneous nanocomposite within the size of 80 nanometers and improvement of the crystalline ordering. The more enhanced $\mathrm{NO}_{2}$ sensing properties have been shown by PPy/rGO- aryl-COOH in terms of higher sensitivity $(1.01 \% / \mathrm{ppm})$, the faster response time (129 s), and the detection limit of (2ppm). Reproducibility features were also investigated.

Moreover, humidity rates and temperature effects were also tested. Finally, impedance spectroscopy is conducted in the fresh air and in the presence of gas. These results highlight the paramount role of functionalization of reduced graphene oxide ( $\mathrm{rGO}-\mathrm{aryl}-\mathrm{COOH})$.

\section{Introduction}

As widely reported through the literature, polypyrrole/graphene nanocomposite is being used in numerous fields such as chemical sensing [1-3], biosensing [4], energy storage and energy conversion [5], electromagnetic absorption [6], and corrosion protection [7] owing to their synergetic effects resulting in improved properties. These features have brought out attention, particularly in the chemical sensing field, through preparing novel materials and sensitives elements attempting to detect nitrogen dioxides $\left(\mathrm{NO}_{2}\right)$. $\left(\mathrm{NO}_{2}\right)$ gas is known for its high toxicity to the environment when getting in contact with oxygen, water, and human health by developing susceptible respiratory infections leading to death. Rules and environmental restrictions have increased the need for its detection at low concentrations, particularly for controlling emissions from different processes [8].

Moreover, $\mathrm{NO}_{2}$ is one of the decomposition products of nitrate ester energetic materials, causing an alteration in their physical and chemical performance properties, leading to auto-ignition under particular conditions occasioning significant damages. Therefore, rapid sensing of $\mathrm{NO}_{2}$ at the ppm level is cruelly needed to overcome all the above-cited problems and anticipate catastrophes. The advanced of the existing sensors based on metal oxides is braked by their high functioning temperatures, reducing their lifecycle stability and making them highly power harvesting. Thus, the present work comes to place a patch in the puzzle by preparing new nanocomposite material and exploring the surface functionalization influence on the expected sensing properties toward nitrogen dioxide.

Polypyrrole (PPy) is attracting more interest from day to day in raison of its rapid and facile synthesis, by chemical, electrochemical, or irradiation techniques (UV, microwaves, and sonochemistry), its electrical conductivity, reduction-oxidation property, and good long-lifetime at room temperature [9]. Moreover, the modification of dopant nature can quickly help to tune the morphology, surface area, and electrical 
properties in the desired applications [10-12], such as gas sensors, lower detection limit, rapid response time, and improved sensitivity is highly required. Although of all what has been experienced about the dopant role in the gas sensors fields [13], there are always some drawbacks that need to be improved. Thus, efforts are now oriented to combining polymers with another nanomaterial to reach more perfection by seeking the synergetic effect and new functionality raising from the two materials. Literature is full of reports, where different strategies of preparing PPy nanostructure with different metals types such as PPy-Ag [14], PPy-Pt [15], PPy-TiO 2 [16], PPy-ZnO [17], PPy/ZnO-SnO 2 [18]; PPy-NiO [19], PPy$\mathrm{WO}_{3}$ [20], $\mathrm{PPy}-\mathrm{Fe}_{2} \mathrm{O}_{3}$ [21], to name but few, have been reported. However, carbon-based nanomaterials, particularly graphene, have attracted much attention owing to the outstanding feature [22], and high chemical stability, making them usable as added charges to conduct sensing processes. Therefore, acceptable sensing performances have been stated when graphene-based gas sensors were used [23,24]. The synthesis of PPy-graphene nanocomposite is divided into two groups: (i) the addition of graphene into the already prepared polymer solution and (ii) in situ addition of graphene during the polymerization reaction. However, the associated problem in these cases is the agglomeration of graphene in the polymer matrix. Therefore, dispersion in organic and aqueous solutions is enhanced by their surface functionalization. Numerous approaches were recommended to tie conductive polymers and graphene. For instance, primeval or oxidized graphene [25], sulfonated graphene was directly polymerized with pyrrole. Recently, reports are portraying new methodologies using diazonium salts as a combination agent [26]. The straightforwardness of procedures has made using diazonium salts a well-dressed technique for treating various surfaces such as semi-conductor, metals, and $\mathrm{sp}^{2}$ carbon. In addition to what aryl diazonium salts could control the interfacial properties, they will increase dispersion in solution. Thus, in the polymer matrix, they will also offer various functional groups to the host polymer to edge sensing. The main descriptions of PPy-graphene nanocomposites preparation are related to their powder form [27]. However, for emerging flexible devices, PPy-Graphene films need a direct deposition onto the flexible substrates. Due to the difficulty of handling such nanocomposite, many procedures were adopted, ranging from the in-situ deposition such as chemical and electrochemical to the ex-situ ones, such as dip coating, spin- coating and drop- coating [28]. Electrochemical techniques have a drawback, as they need electrically conductive substrates, and films obtained from chemical methods suffer from the worst homogeneity, whereas spin coating is simple process providing a deposition of homogeneous thin nanocomposite films on a large variety of insulating substrates with controlled thickness [29].

Hereby, we describe a one-stage synthesis of nanocomposite material based polypyrrole (PPy)/ reduced graphene oxide-grafted carboxybenzene-diazonium salts (PPy/rGO-aryl-COOH). Then, we report a comparison of $\mathrm{NO}_{2}$ sensing on two types of PPy nanocomposites films chemically polymerized with only reduced graphene oxide rGO and others with functionalized reduced graphene rGO-aryl- $\mathrm{COOH}$, and deposited on indium tin oxide (ITO) substrates using spin coating technique. We demonstrate that diazonium functionalized reduced graphene oxide improves the exfoliation and dispersion in the solution and provides a larger molecular function to make PPy-rGO-aryl-COOH exhibiting a larger response to $\mathrm{NO}_{2}$ gas at room temperature (at ( $\mathrm{ppm}$ ) level). Moreover, it shows reversible behavior and stability, which might be offering it a longer working life. 


\section{Experimental}

\subsection{Ingredients}

Pyrrole obtained from (Sigma-Aldrich, within a purity $>98 \%$ ) was refined under reduced pressure and then refrigerated at $4^{\circ} \mathrm{C}$ in the dark. Ammonium Peroxydisulfate and $\mathrm{HCl}$ were purchased from Analar Normapur within a respective purity of $98 \%$ and $37 \%$. Analytical grade solvents and deionized (DI) water were used throughout the preparations. Merck supplied sulfuric acid (H2SO4) (98\%), Potassium permanganate (KMnO4) (98\%), and phosphoric acid (H3PO4) (85\%), Graphite fine powder extra pure ( $\geq$ $99.5 \%$, particles size $<50 \mu \mathrm{m})$, and hydrogen peroxide $\left(\mathrm{H}_{2} \mathrm{O}_{2}\right)(30 \%)$ were acquired from Sigma-Aldrich. 4-Aminobenzoic acid (Reagent Plus $\AA, \geq 99 \%$ ), Isopentyl nitrite $(96 \%)$ is purchased from Sigma Aldrich. The BOPET substrates (thickness, $25 \mu \mathrm{m}$ ) from Sigma-Aldrich. Pieces sizes at $30 \mathrm{~mm} \times 10 \mathrm{~mm}$ to carry out the surface washing. Sheets were cleaned using chloroform, DI water, and ethanol in the ultrasonic bath for $30 \mathrm{~min}$, and then dried out at $70^{\circ} \mathrm{C}$ for $4 \mathrm{~h}$.

\subsection{Techniques}

Spin coater type Ossila is used to prepare thin film layers. FTIR spectrometer type Thermo-Scientific Nicolet 8700 used $4000-400 \mathrm{~cm}^{-1}$ wavenumber with a resolution of $4 \mathrm{~cm}^{-1}$, over 50 scans. Raman diffusion was performed on Thermo-Scientific (RAMAN DXR2) spectrometer. X-ray diffraction (XRD) was realized using a diffractometer type X'Pert PRO (PANalytical) at $45 \mathrm{kV}$ and Cu monochromatic radiation at $(1.54060 \mathrm{~A})$ wavelength, scanning was in the range of $5^{\circ}$ to $90^{\circ}$. SEM images were captured on Microscope type (FEl-Quanta 600). Four-point probe technique type Jandel RM 3000 was used to measure films electrical conductivity.

\subsection{Graphene oxide (GO) preparation}

The graphene oxide (GO) was synthesized according to the improved methods described in work given in [30]. A mixture of $\mathrm{H}_{2} \mathrm{SO}_{4} / \mathrm{H}_{3} \mathrm{PO}_{4}$ at a ratio of $(360: 40 \mathrm{~mL})$ was added to an already prepared solution of graphite (3.0 g, 1 wt equiv) in $\mathrm{KMnO}_{4}\left(18.0 \mathrm{~g}, 6\right.$ wt equiv), generating a rise of temperature to $40^{\circ} \mathrm{C}$. The reaction was then heated to $50{ }^{\circ} \mathrm{C}$ and kept under stirring for $12 \mathrm{~h}$. The reaction cooled to room temperature. Residual permanganate was reduced by adding $3 \mathrm{~mL}$ of $30 \% \mathrm{H}_{2} \mathrm{O}_{2}$ to the suspension, and subsequently, the mixture changed its color from brown to yellow. Finally, filtration and washing were done with aqueous $\mathrm{HCl}$ solution (1:10: $\left.\mathrm{HCl}: \mathrm{H}_{2} \mathrm{O}\right)$ and then distilled water. The resulting solid was dried under air for $20 \mathrm{~h}$ to obtain $\mathrm{GO}$.

\subsection{Preparation of reduced graphene ( $\mathrm{rGO})$}

$100 \mathrm{mg}$ of $\mathrm{GO}$ was mixed with $(100 \mathrm{~mL})$, and then sonicated. The solution was mixed with hydrazine hydrate $(1.00 \mathrm{~mL}, 32.1 \mathrm{mmol})$ and then refluxed for $24 \mathrm{~h}$ until rGO start to precipitate out. The obtained product was filtrated, washed with water $(5 X)$ and methanol $(5 X)$, and then dried [31]. 


\subsection{In-situ functionalization of reduced graphene oxide with aryl 4-carboxybenzene diazonium salt (rGO- aryl-COOH)}

The occurrence of Diazonium functionalization was according to the literature's method and our earlier works [32,33]. An aqueous solution of $1 \mathrm{~g}$ of synthesized $\mathrm{GO}$ in $250 \mathrm{~mL}$ of de-ionized water, was sonicated for $30 \mathrm{~min}$, then $5 \mathrm{~mL}$ of $50 \%$ hydrazine hydrate was dropped. Later, the mixture was subjected to stirring for 4 hours at $100{ }^{\circ} \mathrm{C}$. Diazonium salts was in-situ grafted on the rGO, where $4 \mathrm{~g}$ of 4 aminobenzoic acid and $3 \mathrm{~mL}$ of isopentyl nitrite were vigorously mixed at $80^{\circ} \mathrm{C}$ overnight. The obtained product was filtered and washed with water, followed by dimethylformamide. The black solid eventually dried under high vacuum conditions.

\subsection{Synthesis of Polypyrrole/rGO-aryl-COOH nanocomposites}

Figure 1 shows the different steps of polypyrrole/rGO-aryl-COOH nanocomposites preparation. Dispersion

of $4 \mathrm{mg}$ of rGO-aryl-COOH in $50 \mathrm{~mL}$ of methanol was assisted by ultrasonication for $30 \mathrm{~min}$. Then, $2.23 \mathrm{M}$ of pyrrole was dropped into the solution under continuous ultrasonication for $30 \mathrm{~min}$. While the temperature was maintained close to the range of $0{ }^{\circ} \mathrm{C}$ to $5^{\circ} \mathrm{C}$, the quantity of $2.5 \mathrm{M}$ of $\mathrm{FeCl}_{3}$ was progressively introduced to the mixture of pyrrole and $\mathrm{rGO}$-aryl-COOH then kept under forceful stirring for $6 \mathrm{~h}$. PPy can be grown on the surface of functionalized reduced graphene oxide due to the susceptible hydrogen bonding raising between the carboxybenzene functionalized reduced graphene oxide and polypyrrole. Finally, the obtained nanocomposite was filtered, washed, then dried in a vacuum. The same steps were followed for the preparation of both of PPy/rGO nanocomposite.

\subsection{Nanocomposites thin films preparation for sensing tests}

After the dispersion of $0.1 \mathrm{~g}$ of each PPy nanocomposite with $\mathrm{rGO}$ and $\mathrm{rGO}$-aryl-COOH in acetone under the effect of ultrasonic waves for $30 \mathrm{~min}$, they were then dropped on BOPET to be spin-coated at 1000 rpm for $60 \mathrm{~s}$. Finally, residual acetone was evaporated at $40{ }^{\circ} \mathrm{C}$. As shown in fig.2, obtained films were of homogeneous continuous coating and thickness of $10 \pm 1 \mu \mathrm{m}$.

\subsection{Chemiresistive sensor system set up}

Homemade platform was used to carry out the sensing tests. A legend in Fig. 4 depicts all the related details. Flexible polymer nano-composite placed on mobile piston through a polyethylene tube possessing an inner volume of $60 \mathrm{~mL}$. Set on the top of the tube, a Four-point probe connected to device type Jandel RM3000 for online electrical conductivity measurement. Samples are inserted through a small puncture using a microliter syringe (contact point). We produced the environmental humidity by simple evaporation of distilled water directly connected to the test compartment. The experiments were conducted at temperatures around $25^{\circ} \mathrm{C}$. The exact concentrations of emitted vapors were calculated according to an equation in our previous works on VOC and ammonia sensing [15]. The percent response was determined from the response curves according to the following relations: 
$\mathrm{S}=\frac{\left|\mathrm{R}_{\mathrm{g}}-\mathrm{R}_{\mathrm{a}}\right|}{\mathrm{R}_{\mathrm{a}}} * 100 \%$

When $R_{g}$ is the response value of sensor thin layers under measuring gas, and $R_{a}$ is the response value of fresh air.

\section{Results And Discussion}

\subsection{FTIR characterization}

Figure 5 displays the FTIR spectra of the prepared graphene samples GO, rGO and rGO-aryl-COOH, and their nanocomposites. According to Fig. 5a, for the GO, broadband appeared at the wavenumber of approximately $3428 \mathrm{~cm}^{-1}$ characteristics of the $\mathrm{OH}$ elongation vibration of the $-\mathrm{COOH}$ groups and water molecules interspersed. Also, the elongation $C=0$ was seen at $1720 \mathrm{~cm}^{-1}$, while the stretch of epoxy group C-O-C can be observed at a wavenumber of $1298 \mathrm{~cm}^{-1}$ and at $1008 \mathrm{~cm}^{-1}$ [34]; the peaks at 1069 and $1170 \mathrm{~cm}^{-1}$ are attributed to the $\mathrm{C}-0$ bond of the alkoxyl and carboxyl groups, respectively. The peak found at $885 \mathrm{~cm}^{-1}$ has been ascribed to aromatic $\mathrm{C}-\mathrm{H}$ bonds of pyrrole [34]. In all of these groups, it has been confirmed that oxygen molecules strongly occupy the edges and surfaces of GO. It can be concluded that $\mathrm{GO}$ has been successfully synthesized.

In Fig. 5b, the peak at $3439 \mathrm{~cm}^{-1}$ has become narrower compared to that of $\mathrm{rGO}$, showing that the hydroxyl and carboxyl group have been eliminated significantly. We noted the intensity reduction of the other peaks at 1720,1298,1008, 1069 and $885 \mathrm{~cm}^{-1}$. Therefore, peaks at 1637,1444 and $1119 \mathrm{~cm}^{-1}$, can be affected by the extending vibration of the $\mathrm{C}=\mathrm{C}$ bond, the $\mathrm{C}-\mathrm{OH}$ strain vibration, and the $\mathrm{C}-\mathrm{O}$ elongation of the alcohol group, respectively [34]. Consequently, the oxygen-containing functional groups have been partially eliminated from the $\mathrm{GOO}$ with success, and small functional group residues have still persisted at the peripheral and basal plane of rGO.

The FTIR spectrum of rGO-aryl-COOH presented in Fig. $5 \mathrm{c}$, shows: a wide and intense band at $3422 \mathrm{~cm}^{-1}$, which is distinctive of the $\mathrm{COOH}$ groups elongating vibration, a peak at $1723 \mathrm{~cm}^{-1}$ attributed to $\mathrm{C}=0$ stretching of the $-\mathrm{COOH}$ group and a peak at $1561 \mathrm{~cm}^{-1}$ corresponds to the vibrations of the $\mathrm{C}=\mathrm{C}$ bonds. This indicates the presence of an Aryl-COOH group. The peaks at 2926 and $2856 \mathrm{~cm}^{-1}$ have been attributed to the $\mathrm{C}-\mathrm{H}$ stretching vibration of the $\mathrm{sp}^{3}$ carbon, which proves that the Aryl-COOH functional groups had been effectively grafted on top of the surface of $\mathrm{rGO}$.

The assessment of Fig.5b related to PPy / rGO composite shows the presence of polypyrrole characteristic peaks at 1551 and $1315 \mathrm{~cm}^{-1}$ (the elongation $\mathrm{C}-\mathrm{C}$ and $\mathrm{C}-\mathrm{N}$ of the pyrrole ring). The peak at $1040 \mathrm{~cm}^{-1}$ corresponds to the $\mathrm{C}-\mathrm{H}$ vibrations of the ring pyrrole in the plane. The peaks at 923 and 1180 $\mathrm{cm}^{-1}$ are allotted to the bipolar state of PPy [35]. The peaks corresponding to the $\mathrm{C}-\mathrm{H}$ strain vibration of the polymer ring off-plan are observed at around $781 \mathrm{~cm}^{-1}[36]$. 
Spectra Fig. 5c, of PPy/ rGO-aryl-COOH shows the presence of peaks due to oxygen functional groups, in addition to the characteristic peaks of PPy, at 1494, 1367,1206 and $929 \mathrm{~cm}^{-1}$, which can be attributed to the $\mathrm{C}-\mathrm{C}$ and $\mathrm{C}-\mathrm{N}$ elongation of the pyrrole ring and the bipolar state of PPy, respectively [35]. The wideband at $3469 \mathrm{~cm}^{-1}$ can be assigned to the amine groups of the polypyrrole and $\mathrm{O}-\mathrm{H}$ groups in rGOaryl- $\mathrm{COOH}$. The peaks at 1741 and $1600 \mathrm{~cm}^{-1}$ are attributed to carbonyl groups and the bond $\mathrm{C}=\mathrm{C}$, respectively, which confirms the polymerization of PPy and the composite formation [37].

\subsection{Raman characterization}

Figure 6 illustrates Raman spectra, GO, rGO and rGO-aryl-COOH, and Table 1 lists the characteristics of the latter. Raman spectroscopy is very useful for observing structural changes in the samples through oxidation, exfoliation, reduction, and functionalization. The $\mathrm{D}$ band and the $\mathrm{G}$ band, characteristic of graphene have been demonstrated. Generally, the $\mathrm{G}$ band corresponds to the bonds of the $\mathrm{sp}^{2}$ carbons in a conjugated carbon network [38]. The D band (or diamond band) is only observed in defects corresponding to the signal of the sp3 carbons present in a carbon crystal such as a diamond. It is observed only in defective graphene [39]. Defects density can be estimated by measuring the ratio between intensity $\left(I_{D} / I_{G}\right)$ of the $D$ band and the $G$ band $[38,39]$.

A sharp and intense $G$ band at $1568 \mathrm{~cm}^{-1}$ and a feeble $D$ band at $1345 \mathrm{~cm}^{-1}$ can be found in the graphite sample with a low $I_{D} / I_{G}$ value of 0.31 , indicating the presence of the $\mathrm{sp}^{2}$ hybrid carbon atoms with a minimal number of defects [38]. Another single peak perceptible at $2700 \mathrm{~cm}^{-1}$, indicating the stacking of graphitic multilayers [39].

When oxidizing the graphite, the $\mathrm{GO}$ sample shows an intense $\mathrm{D}$ band at $1364 \mathrm{~cm}^{-1}$, while the $\mathrm{G}$ band widened and moved to an upper wavenumber at $1614 \mathrm{~cm}^{-1}$, caused by the presence of isolated double bonds, which demonstrates the introduction of defects in the structure of graphene by the incorporation of oxygen groups [7]; therefore, the corresponding ratio $I_{D} / I_{G}$ augmented to 1.02. A smaller defect density with an $I_{D} / I_{G}$ ratio of 1.00 was observed after hydrazine reduction in $\mathrm{rGO}$ spectra. The $G$ band has also shifted to an inferior wavenumber $\left(1574 \mathrm{~cm}^{-1}\right)$, signifying the regaining of the $\mathrm{sp}^{2}$ domain of graphene to some extent by removing oxidizing groups [40].

After $\mathrm{rGO}$ functionalization, an increase of $\mathrm{I}_{\mathrm{D}} / \mathrm{I}_{\mathrm{G}}$ ratio around 1.02 was observed, attributed to the aryl functions grafting. The $G$ band has shifted slightly to a lower wavenumber $p 1573 \mathrm{~cm}^{-1}$, which signifies the increase in the $\mathrm{sp}^{2}$ domain and which may be due to the benzene rings of the Aryl group.

On the other hand, the 2D band consists of two peaks named 2D and D + D ', as observed in the Raman spectra of the samples $\mathrm{GO}$ and $\mathrm{rGO}$ and $\mathrm{rGO}-\mathrm{aryl}-\mathrm{COOH}$, which indicates a decrease in the number of layers of graphene in these samples compared to the graphite sample [39].

The superposition of the Raman spectra of the composites PPy / GO, PPy / rGO and PPy / rGO-aryl-COOH with their charges is illustrated in Fig.7 the corresponding values are precised in Table 2. 
There are two peaks around the $D$ band and the $G$ band within all samples, the relatively large shape suggests a partially disordered structure demonstrating short conjugation sequences. There is also a decrease in the composites $I_{D} / I_{G}$ ratios compared to their pure fillers, indicating the increase in the $\mathrm{sp}^{2}$ domain, which may be due to incorporating polypyrrole into the material. Compared to the starting charges, the $\mathrm{D}$ and $\mathrm{G}$ bands have changed to lower wavenumbers, demonstrating that the conductive polymers do interact with the charge [41].

The PPy / GO spectrum can be seen as an appearance of low-intensity peaks at $615 \mathrm{~cm}^{-1}$ (torsion ring), at 940 and $992 \mathrm{~cm}-1$, which matches the polaronic and bipolaronic quinoid structure, respectively. Regarding the rGO / PPy spectrum, two more peaks are observed at 968 and $1042 \mathrm{~cm}^{-1}$, which correspond to the deformation of the bipolar [12].

The Raman spectra of the nanocomposites PPy/ rGO-aryl-COOH shows four new peaks from the PPy can be indexed at $930,959,1057$ and $1244 \mathrm{~cm}^{-1}$, except the $D$ and $\mathrm{G}$ bands of the rGO-aryl-COOH sheets, which correspond to the polaronic structure, bipolaronic quinoid, symmetric and antisymmetric $\mathrm{CH}$ bending vibration in the polaron plane, respectively [12]. Leading to high conductivity [10].

\subsection{X-ray diffraction Characterization}

Aiming to get more insight, a comparison between X-ray diffraction patterns of GO, rGO, and rGO-aryl$\mathrm{COOH}$ is shown in Fig. 8. The graphite showed a sharp, high intensity diffraction peak, at a value of $2 \theta$ of about $26.41^{\circ}$, with a parameter $\mathrm{hkl}(002)$. This result confirms the arranged layer structure with an inter distance $\left(\mathrm{d}_{002}\right)$ of $0.334 \mathrm{~nm}$ along with the $(002)$ orientation and which is consistent with the reported literature [42].

The DRX profile of the $\mathrm{GO}$ shows a new peak at $2 \theta=9.4^{\circ}$, with a parameter hkl (002). It arises from the presence of both of $\mathrm{sp}^{2}$ domains of graphene and oxidized $\mathrm{sp}^{3}$ domains [43]. As a result, the interlayer distance increased $\left(\mathrm{d}_{002}=0,92 \mathrm{~nm}\right)$. This has been accredited to the spacing induced by the presence of functional oxygen groups and water molecules in the interlayer space of GO [43].

After the chemical reduction of GO, a wider peak is observed for $\mathrm{rGO}$ at $2 \theta=26.19^{\circ}$, thus a significant decrease (or disappearance) of the peak at $2 \theta=9.4^{\circ}$. This points out that the $\pi$-conjugated structure of graphene has been significantly reinstated [42]. Also, the $d_{002}$ spacing of $r G O$ was reduced to $0.34 \mathrm{~nm}$, demonstrating the removal of the functional groups containing oxygen.

The broad peak at $2 \theta=26.19^{\circ}$ for $\mathrm{rGO}$ implies the random arrangement of the crystal phase (002) for the high crystallization structure of graphite [60]. In the rGO-aryl-COOH diffractogram, we notice the appearance of new peaks, very sharp at the different Bragg angles $\left(2 \theta=\left\{16.67^{\circ} ; 17.41^{\circ} ; 18.47^{\circ} ; 25.08^{\circ}\right.\right.$; $\left.\left.26,31^{\circ} ; 29.26^{\circ}\right\}\right)$, which can probably be linked to the crystallization of the Aryl functions. This is possibly due to the self-organization of the aryl groups and grafting of the latter at well-determined positions in the rGO plan [44]. 
PPy/ rGO composite presented on Figure 9 shows a wide halo at $2 \theta=26.14^{\circ}$, typical of PPy, indicating the presence of an amorphous part in the composite [5]. In contrast, the original diffraction peak of rGO disappeared. Indicating the exfoliation of rGO and the PPy chain are formed on the rGO surface during the polymerization reaction [3].

The PPy/ rGO-aryl-COOH composite in Fig. 9 had a wide peak at $25^{\circ}$, representing the existence of PPy. In addition, the characteristic peaks of rGO-aryl-COOH disappeared in the PPy / $\mathrm{rGO}$-aryl-COOH composite, indicating that $\mathrm{rGO}$-aryl- $\mathrm{COOH}$ showed no accumulation and was used entirely as a substrate for PPy [3].

\subsection{SEM Characterization}

Figure 10a, shows the micrograph of reduced graphene oxide ( $\mathrm{rGO})$. The surface contained thin crumpled leaves, which are settled randomly, tightly associated with each other to form a disordered structural material [45]. The Van der Waals interaction between graphene layers leads to a significant agglomeration due to being highly hydrophobic.

The SEM on Figure 10b, of the functionalized reduced graphene oxide rGO-aryl-COOH, presents a morphology of crumpled thin sheets, which gives it a large surface area. It can also be observed that the shape of the peripheral contour of carboxybenzene-functionalized graphene is tilted because of the carboxyl group effect.

Figure 10c shows the formation of highly agglomerated PPy/rGO nanocomposite, probably caused by the strength of the hydrogen bond and the $\boldsymbol{\Pi}-\boldsymbol{\Pi}$ interaction between pyrrole and rGO [46]. In contrast, Figure $10 \mathrm{~d}$ shows the of PPy/rGO-aryl-COOH nanocomposite. PPy has a wrinkled shape forming a mesh structure, grown on the surface of functionalized reduced graphene oxide nanosheets, indicating that the PPy network is firmly joined with the graphene nanosheets. These morphological features are likely to play a considerable role in $\mathrm{NO}_{2}$ absorption because it provides a large adsorption surface and facilitates the adsorption of $\mathrm{NO}_{2}$.

\subsection{Conductivity measurements}

Table 3 gives the room temperature electrical conductivity values of ( $\sigma$ ) PPy/rGO and PPy/ rGO-aryl$\mathrm{COOH}$ nanocomposite, where the film (PPy/ rGO-aryl-COOH) shows the higher values. These propose that the PPy developed on the carboxyl-benzene functionalized graphene has a better chain arrangement, increasing the PPy/ rGO-aryl-COOH conductivity. This could be related to the electron-withdrawing groups rising from carboxyl-benzene functionalization, thus expanding the electron transfer density between the graphene plane and the carboxyl group. This increase in density leads to a rise in conductivity [47]. The variation of conductivity can be regarded from SEM results and X-ray diffraction obtained earlier in figures 8,9 and 10, where the crystallinity of PPy chain structure conferred by grafted presence rGO-aryl$\mathrm{COOH}$ sheets as well as they help the inter-chain hopping of charge carriers.

\subsection{Chemiresistive gas sensing characteristics}


On Figure 11, we investigate the comparison of the sensing selectivity of nano-composite PPy/rGO and $\mathrm{PPy} / \mathrm{rGO}$-aryl-COOH toward the same concentration of different gases $\mathrm{NO}_{2}, \mathrm{NH}_{3}, \mathrm{H}_{2} \mathrm{~S}$ and $\mathrm{SO}_{2}$. $\mathrm{PPy} / \mathrm{rGO}$ aryl- $\mathrm{COOH}$ thin film has shown big selectivity to $20 \mathrm{ppm}$ of $\mathrm{NO}_{2}$ over the former gases. The high selectivity of PPy/rGO-aryl-COOH establishes a suitable material for detecting $\mathrm{NO}_{2}$ gas at low concentration. This selectivity improvement is credited to the synergistic effect of $\mathrm{rGO}$-aryl-COOH and PPy.

\subsubsection{Response time}

As shown in Figure 12, the response time was observed very fast, around 129s and 199s for the nanocomposites PPy/ rGO-aryl-COOH and PPy/rGO, respectively. However, after removing the external excitation, the recovery time was found around $114 \mathrm{~s}$ and $145 \mathrm{~s}$ for the nanocomposites PPy/ rGO-aryl$\mathrm{COOH}$ and $\mathrm{PPy} / \mathrm{rGO}$, respectively. This emphasizes the effect of the surface functionalization on the performances of the principal sensor.

\subsubsection{Static study}

Repeatability of the PPy/rGO and PPy/ rGO-aryl-COOH based gas sensor is given in Fig. 13; five rounds of responses to $\mathrm{NO}_{2}$ have been completed within the exposition of the nanocomposites to $2 \mathrm{ppm}$. An excellent repeatable and stable behavior is observed after cycles for gas sensing. Nitrogen dioxide a strong oxidant, $\mathrm{PPy} / \mathrm{rGO}$-aryl-COOH and PPy/rGO exhibit preferentially the $\mathrm{p}$-type behavior, causing a proliferation of charge carriers number decrease in the nanocomposites resistances. The composite $\mathrm{PPy} / \mathrm{rGO}$-aryl-COOH showed a high response to $\mathrm{PPy} / \mathrm{rGO}$ due to the diazonium functionalization of the withdrawing groups. Furthermore, the charge transfer between PPy and rGO-aryl-COOH can be more efficient due to the interfacial affinity provided by the interaction of carboxyl groups and non-binding nitrogen atom doublet of polypyrrole. Also, the carboxyl groups can probably participate in the sensor response by favoring $\mathrm{NO}_{2}$ adsorption.

\subsubsection{Dynamic study}

$\mathrm{NO}_{2}$ concentrations ranging in the 1-20 ppm were injected as illustrated on Fig. 14. Change in the curve response amplitude was observed proportionally when increasing $\mathrm{NO}_{2}$ concentration. The amplitude is more intense, notably PPy/rGO-aryl-COOH. This put forward role of functionalization in improving the sensor response. During the recovery process, both of the tested films rapidly regain the baseline, signing their reversibility. The PPy/ rGO-aryl-COOH nanocomposite shows encouraging prospects as a potential material for NO2 detection in atmospheric conditions in terms of comparison between the two-tested nano-composites.

\subsubsection{Sensors response under temperature variation}

As the PPy/ rGO-aryl-COOH has shown high response performances, the following sections are dedicated only to the behavior study of PPy/ rGO-aryl-COOH. Aiming to follow temperature influences, PPy/ rGO- 
aryl- $\mathrm{COOH}$ was heated into different temperatures and values until $80^{\circ} \mathrm{C}$. The corresponding responses are presented in Fig. 15 and deduced sensitivity values are given in Table 4 below. Although the applied temperature environment has a total of sensitivity reduction around $20 \%$, such comportment could reduce site activity in the composite layer and hamper the interactions development. However, we can observe that temperature doesn't affect the sensitivity significantly in an immense magnitude, confirming that $\mathrm{PPy} / \mathrm{rGO}$-aryl-COOH preserve its performances even under a variable temperature environment

\subsubsection{Influence of relative humidity}

Injection of 2-ppm concentration of $\mathrm{NO}_{2}$ gas was carried out under a humid atmosphere. A hygrometer (Omega type $\mathrm{HH} 314 \mathrm{~A}$ ) was used to indicate The relative humidity $(\mathrm{RH})$ generated by injecting water vapor in the test chamber at rates ranging from $20 \%$ to $80 \%$, as illustrated in Fig. 4 . The inverse proportionality of the sensor response with humidity shown in Fig. 16, demonstrates a diminution more than $50 \%$, establishing the substantial humidity impact on sensor efficiency. This result may be due to inhibition of the active site by a hydroxyl group, when they are bridged with carboxylic entities through a hydrogen bond.

\subsubsection{Impedance spectroscopy study}

Impedance spectroscopy is used to characterize contributions arising from the interactions of different components of PPy/ rGO-aryl-COOH and PPy/rGO film with the gas. Two environments were used to conduct the impedance measurements (pure air and $\mathrm{NO}_{2}$ at a concentration of $20 \mathrm{ppm}$ ). Figure 17 shows the plot obtained spectra in the form of Nyquist. Resulted impedance spectra are plotted from low frequency to high frequency region in the form of a semi-circle, the obtained values can be set into an equivalent circuit as presented in Fig. 18, consisting of free frequency resistance $\left(R_{0}\right)$, resistance $\left(R_{1}\right)$ and capacitor $\left(C_{1}\right)$ in parallel. Figure 17 , shows the identification between experimental data and fitted curve. Table 5 presents the physical measurements before and after exposure to $\mathrm{NO}_{2}$ gas. It was found that $\mathrm{R}_{0}$ is the same in gas and air conditions. However, $R_{1}, R_{2}$ and $C_{1}$ do not alter dramatically when exposed to the $\mathrm{NO}_{2}$ gas. This finding is supported by the fact that upon interaction of $\mathrm{NO}_{2}$ with $\mathrm{PPy}$, charge carriers are produced at the surface of PPy, lowering the inter-grains resistance, on the one hand, facilitating charge transfer between PPy and rGO, and thus increasing the inter-grains capacitance, on the other hand.

Table 6 presents a comparison of chemiresistive sensors performances according to the materials nature based as the sensing interfaces.

\section{Conclusions}

A flexible nanocomposite of polypyrrole with graphene functionalized surface film destined as dioxide nitrogen sensor has been elaborated following in situ one-step polymerization of pyrrole at room temperature. Surface functionalization of reduced graphene oxide by diazonium salts type carboxy- 
benzene has enhanced its crystallinity and, thus, nanocomposite, further improved electric conductivity. After investigations with various gases, observations have put forward the aptitude of detection selectivity toward nitrogen dioxide gas above the other vapors. The PPy/ rGO-aryl-COOH film displays good features notably (response time within few minutes, and sensitivity in (1-20 ppm) range exposure comparatively to nanocomposite film prepared only with reduced graphene, highlighting the paramount impact of surface functionalization rising from the presence of carboxylic groups which has proven its ability and capability to develop bonds with nitrogen dioxide, and influence furtherly the whole sensitivity. Moreover this founds come to confirm what was reported in the literature about the contribution of such function groups in regulating the sensor performances. The sensitivity of PPy/ rGO-aryl-COOH remains considerable under varied temperature, indicating its function ability under harsh environment film. Moreover, even with the different rates of applied humidity, the film has kept an acceptable sensitivity. Hence, PPy/rGO-aryl-COOH can be classified as one of the promising sensitive materials for dioxide nitrogen gas detection.

\section{Declarations}

\section{Acknowledgments}

Ecole Militaire Polytechnique financially hosted this work through the providing of a Ph.D. scholarship project N ${ }^{\circ}$ 2/17/DRFPG/CMDT for GUETTICHE Djamil. The authors are also grateful to the DGRSDT/MESRS for providing assistance to this work.

\section{Ethical procedures}

The paper is submitted with complete responsibility, respecting the ethical procedure; where all concerns related to animal or human experimentation are totally discarded. Moreover, all kind of duplication, fraud or plagiarism have been correctly checked and refined.

\section{A disclosure / conflict of interest statement}

None of the authors of this paper has a financial or personal relationship with other people or organizations that could inappropriately influence or bias the content of the paper. It is to specifically state "No Competing interests are at stake and there is No Conflict of Interest" with other people or organizations that could inappropriately influence or bias the content of the paper.

\section{References}

[1] Parthasarathy Srinivasan, Madeshwari Ezhilan, Arockia Jayalatha Kulandaisamy, K. Jayanth Babu, John Bosco Balaguru Rayappan, Room temperature chemiresistive gas sensors: challenges and strategies-a mini review. J Mater Sci: Mater Electron 30, 15825-15847 (2019) 
[2] S. R. Nalage, M. A. Chougule, Shashvati Sen, V. B. Patil, Novel method for fabrication of NiO sensor for $\mathrm{NO}_{2}$ monitoring. J Mater Sci: Mater Electron 24, 368-375

[3] W.-K. Jang, J. Yun, H.-I. Kim, Y. S. Lee, Improvement of ammonia sensing properties of polypyrrole by nanocomposite with graphitic materials. Colloid Polym. Sci. 291, 1095-1103 (2013)

[4] C. Ott and al, Functionalized polypyrrole/sulfonated graphene nanocomposites: Improved biosensing platforms through aryl diazonium electrochemistry. Synth. Met. 235, 20-28 (2018)

[5] Abu Jahid Akhtar, Shubhankar Mishra, Sudip Kumar Saha, Charge transport mechanism in reduced graphene oxide/polypyrrole based ultrahigh energy density supercapacitor. J Mater Sci: Mater Electron 31, 11637-11645 (2020)

[6] F. Wu, A. Xie, M. Sun, Y. Wang, M. Wang, Reduced graphene oxide (RGO) modified sponge like polypyrrole (PPy) aerogel for excellent electromagnetic absorption. J. Mater. Chem. A. 3, 14358-14369 (2015)

[7] M. Marimuthu and al, Sodium functionalized graphene oxide coated titanium plates for improved corrosion resistance and cell viability. Appl. Surf. Sci. 293, 124-131 (2014)

[8] T. Boningari, P. G. Smirniotis, Impact of nitrogen oxides on the environment and human health: Mnbased materials for the $\mathrm{NO}_{x}$ abatement. Curr. Opin. Chem. Eng. 13, 133-141 (2016)

[9] M. Das, S. Roy, Polypyrrole and associated hybrid nanocomposites as chemiresistive gas sensors: A comprehensive review. Mater. Sci. Semicond. Process. 121, 105332 (2021)

[10] A. T. Mane, S. D. Sartale, V. B. Patil, Dodecyl benzene sulfonic acid (DBSA) doped polypyrrole (PPy) films: synthesis, structural, morphological, gas sensing and impedance study. J Mater Sci: Mater Electron 26, 8497-8506 (2015)

[11] S. Geetha, D. C. Trivedi, Synthesis, characterization and temperature studies on the conductivity of AlCl-4 ion doped polypyrrole. J Mater Sci: Mater Electron 16, 329-333 (2005)

[12] Shruti Peshoria, Anudeep Kumar Narula, Study and explanation about the morphological, electrochemical and structural properties of differently synthesized polypyrrole. J Mater Sci: Mater Electron. 28, 18348-18356 (2017)

[13] F. Merdj, A. Mekki, D. Guettiche, B. Mettai, Z. B. D. Sayah, Z. Safidine, A. Abdi, R. Mahmoud, Macromol. Res. (2018) https://doi.org/10.1007/s13233-018-6069-1

[14] J. Zhang, X. Liu, S. Wu, H. Xu, B. Cao, One-pot Fabrication of Uniform Polypyrrole/Au Nanocomposites and Investigation for Gas Sensing. Sens. Actuators B 186, 695-700 (2013) 
[15] Namrata Gaikwad, Sreenu Bhanoth, Priyesh. More, G. H. Jainb and P. K. Khanna, Chemically designed Pt/PPy nano-composite for effective LPG gas sensor. J. Nanosci. 6, 2746-2751 (2014)

[16] M. Kumaresan, M. Venkatachalam, M. Saroja, P. Gowthaman, Significant enhancement in the hydrogen-sensing performance of polypyrrole/titanium oxide $\left(\mathrm{PPy} / \mathrm{TiO}_{2}\right)$ hybrid sensors by a chemical oxidation polymerization approach. J Mater Sci: Mater Electron 31, 8183-8193 (2020)

[17] H. Albaris,G. Karuppasamy, CuO-ZnO p-n junction enhanced oxygen sensing property of polypyrrole nanocomposite at room temperature. J Mater Sci: Mater Electron 30, 9989-9998 (2019)

[18] H. A. Khorami, A. Eghbali, M. Keyanpour-Rad, M. R. Vaezi, M. Kazemzad, Ammonia sensing properties of (SnO2-ZnO)/polypyrrole coaxial nanocables. J. Mater. Sci. 49, 685-690 (2014)

[19] S.R. Nalage, S.T. Navalea, R.S. Manec, Mu. Naushad, F.J. Stadlarb, V.B. Patila, Preparation of camphor-sulfonic acid doped $\mathrm{PPy}-\mathrm{NiO}$ hybrid nanocomposite for detection of toxic nitrogen dioxide. Synth. Met. 209, 426-433 (2015)

[20] A.T. Mane, S.T. Navale, V.B. Patil, Room temperature $\mathrm{NO}_{2}$ gas sensing properties of DBSA doped PPy-WO3 hybrid nanocomposite sensor. Org. Electron. 19, 15-25 (2015)

[21] S.T. Navale, G.D. Khuspe, M.A. Chougule, V.B. Patiln, Room temperature NO2 gas sensor based on PPy/a-Fe2O3 hybrid nanocomposites. Ceram. Int. 40, 8013-8020 (2014)

[22] A. K. Geim, K. S. Novoselov, The rise of graphene. Nanosci. Technol.: Int. J. (2009) https://doi.org/10.1142/9789814287005_0002

[23] GRavi Kumar, Anil Kumar, Rakesh Singh, Rajesh Kashyap, Dinesh Kumar, Rajesh Goel, Mukesh Kumar. J Mater Sci: Mater Electron (2021). https://doi.org/10.1007/s10854-020-04940-0

[24] S. Basu et P. Bhattacharyya, Recent developments on graphene and graphene oxide based solid state gas sensors. Sens. Actuators B 173, 1-21 (2012)

[25] H. Bai, K. Sheng, P. Zhang, C. Li and G. Shi, Graphene oxide/conducting polymer composite hydrogels. J. Mater. Chem. 21, 18653 (2011)

[26] C. Cao, Y. Zhang, C. Jiang, M. Qi, and G. Liu, Advances on Aryldiazonium Salt Chemistry Based Interfacial Fabrication for Sensing Applications. ACS Appl. Mater and Interfaces. 9, 5031-5049 (2017)

[27] S. Bose, T. Kuila, M. E. Uddin, N. H. Kim, A. K.T. Lau, J. H. Lee, In-situ synthesis and characterization of electrically conductive polypyrrole/graphene nanocomposites. Polymer. 51, 5921-5928 (2010)

[28] Metin Yurddaskal, Mustafa Erol, Erdal Celik, Carbon black and graphite filled conducting nanocomposite films for temperature sensor applications. J Mater Sci: Mater Electron. 28, 9514-9518 (2017) 
[29] S.T. Navale, A. T. Mane, M. A. Chougule, R. D. Sakhare, S.R. Nalage, V.B. Patil, Highly selective and sensitive room temperature $\mathrm{NO}_{2}$ gas sensor based on polypyrrole thin films. Synth. Met. 189, 94-99 (2014)

[30] D. C. Marcano, D. V. Kosynkin, J. M. Berlin, A. Sinitskii, Z. Sun, A. Slesarev, Lawrence B. Alemany, Wei Lu, J. M. Tour, Improved Synthesis of Graphene Oxide. ASC Nano. 4 ,4806-4814 (2010)

[31] S. Stankovich, D. A. Dikin, R. Piner, K. A. Kohlhaas, A. Kleinhammes, Y. Jia, Y. Wu, S. B. T. Nguyen, R. S. Ruof, Synthesis of graphene-based nanosheets via chemical reduction of exfoliated graphite oxide. Carbon. 45, 1558-1565 (2007)

[32] A. A. Mohamed, Z. Salmi, S. A. Dahoumane, A. Mekki, B. Carbonnier, M. Chehim, Functionalization of nanomaterials with aryldiazonium salt. Adv. Colloid Interface Sci. 225, 16-36 (2015)

[33] A. Bensghaïer, Z. Salmi, B. L. Droumaguet, A. Mekki, A. A. Mohamed, M. Bejia and M. M. Chehimib, Diazonium interface chemistry and click polymerization: A novel route for carbon nanotube-polytriazole nanocomposites. Surf. Interface Anal. 48, 509-513 (2016)

[34] M. P. Lavin-Lopez, A. Paton-Carrero, L. Sanchez-Silva, J. L. Valverde, A. Romero, Influence of the reduction strategy in the synthesis of reduced graphene oxide. Adv. Powder Technol. 28, 3195-3203 (2017)

[35] Y. Han and al, Preparation and electrochemical performances of graphene/polypyrrole nanocomposite with anthraquinone-graphene oxide as active oxidant. Carbon. 119, 111-118, (2017)

[36] Z. Gu and al, Synthesis and characterization of polypyrrole/graphite oxide composite by in situ emulsion polymerization. J. Polym. Sci. Part B Polym. Phys. 48, 1329-1335 (2010)

[37] R. Bissessur, P. K. Y. Liu, S. F. Scully, Intercalation of polypyrrole into graphite oxide. Synth. Met. 156, 1023-1027 (2006)

[38] M. S. Dresselhaus, A. Jorio, M. Hofmann, G. Dresselhaus, R. Saito, Perspectives on Carbon Nanotubes and Graphene Raman Spectroscopy. Nano Lett. 10, 751-758 (2010)

[39] D. Graf and al, Spatially Resolved Raman Spectroscopy of Single- and Few-Layer Graphene. Nano Lett. 7, 238-242 (2007)

[40] K. N. Kudin, B. Ozbas, H. C. Schniepp, R. K. Prud'homme, I. A. Aksay, R. Car, Raman Spectra of Graphite Oxide and Functionalized Graphene Sheets. Nano Lett. 8, 36-41 (2008)

[41] J. Zhang, X. S. Zhao, Conducting Polymers Directly Coated on Reduced Graphene Oxide Sheets as High-Performance Supercapacitor Electrodes. J. Phys. Chem. C. 116, 5420-5426 (2012) 
[42] Yongan Niu, Qiuming Zhang, Yao Li, Qinghong Fang, Xin Zhang, "Reduction, dispersity and electrical properties of graphene oxide sheets under low-temperature thermal treatments". J Mater Sci: Mater Electron. 28, 729-733 (2017)

[43] K. Krishnamoorthy, M. Veerapandian, K. Yun, S.-J. Kim, The chemical and structural analysis of graphene oxide with different degrees of oxidation. Carbon. 53, 38-49 (2013)

[44] S. Park , Jinho An, Jeffrey R. Potts , Aruna Velamakanni , Shanthi Murali , Rodney S. Ruoff, Hydrazine-reduction of graphite and graphene oxide. Carbon. 49, 3019 -3023 (2011)

[45] S.T. Navale, A.T. Mane, M.A. Chougule, N. M. Shinde, Highly selective and sensitive CdS thin film sensors for detection of $\mathrm{NO}_{2}$ gas. RSC Adv. 4, 44547-44554 (2014)

[46] L. Q. Fan, G. J. Liu, J. H. Wu, L. Liu, J. M. Lin, Y. L. Wei, Asymmetric supercapacitor based on graphene oxide/polypyrrole composite and activated carbon electrodes. Electrochim. Acta. 137, 26-33 (2014)

[47] M Fang, K Wang, H Lu, Y Yang, S Nutt., Single-layer graphene nanosheets with controlled grafting of polymer chains. J. Mater. Chem. 20, 1982-1992 (2010)

[48] P. Su, H. Shieh, Flexible $\mathrm{NO}_{2}$ sensors fabricated by layer-by-layer covalent anchoring and in situ reduction of graphene oxide. Sens. Actuators B 190, 865-872 (2014)

[49] R. Kumar, S. Singh, A. Misra, Development of $\mathrm{NO}_{2}$ Gas Sensor Based on Plasma Polymerized Nanostructure Polyaniline Thin Film. J. Miner Mater Char Eng. 9, 997 (2010)

[50] M. A. Chougule, D. S. Dalavi, S. Mali, P. S. Patil, A. V. Moholkar, G. L. Agawane, J. H. Kim, S. Sen, V.B. Patil, Novel method for fabrication of room temperature polypyrrole-ZnO nanocomposite $\mathrm{NO}_{2}$ sensor. Measurement. 45, 1989 (2012)

[51] Tien, H.N. Hur, S.H. One-step synthesis of a highly conductive graphene-polypyrrole nanofiber composite using a redox reaction and its use in gas sensors. Phys. Status Solidi Rapid Res. Lett. 6, 379381 (2012)

[52] Y. Yang, S. Li, W. Yang, W. Yuan, J. Xu, Y. Jiang, In Situ Polymerization Deposition of Porous Conducting Polymer on Reduced Graphene Oxide for Gas Sensor. ACS Appl. Mater. Interfaces. 6, 13807-13814 (2014)

\section{Tables}

Table 1 Structural characteristics of Graphitic materials 


\begin{tabular}{|llllll|}
\hline & $\mathbf{D}\left(\mathbf{c m}^{-1}\right)$ & $\mathbf{G}\left(\mathbf{c m}^{-1}\right)$ & $\mathbf{2 D}\left(\mathbf{c m}^{-1}\right)$ & $\mathbf{D}+D^{\prime}\left(\mathbf{c m}^{-1}\right)$ & $\mathrm{I}_{\mathbf{D}} / \mathrm{I}_{\mathbf{G}}$ \\
\hline Graphite & 1345 & 1568 & 2700 & $/$ & 0,31 \\
\hline GO & 1364 & 1614 & 2704 & 2950 & 1,02 \\
\hline rGO & 1350 & 1574 & 2658 & 2919 & 1,00 \\
\hline rGO-aryl-COOH & 1350 & 1573 & 2682 & 2921 & 1,02 \\
\hline
\end{tabular}

Table 2 Structural characteristics of composites

\begin{tabular}{|llll|}
\hline & $\mathbf{D}\left(\mathrm{cm}^{-1}\right)$ & $\mathbf{G}\left(\mathbf{c m}^{-1}\right)$ & $\mathrm{I}_{\mathbf{D}} / \mathrm{I}_{\mathbf{G}}$ \\
\hline $\mathrm{PPy} / \mathrm{GO}$ & 1338 & 1557 & 1,01 \\
\hline $\mathrm{PPy} /$ rGO & 1335 & 1560 & 0,89 \\
\hline $\mathrm{PPy} /$ rGO-aryl-COOH & 1349 & 1570 & 0,84 \\
\hline
\end{tabular}

Table 3 Conductivities of PPy/rGO and PPy/ rGO-aryl-COOH at room temperature

\begin{tabular}{|lll|}
\hline Composites films & $\begin{array}{l}\text { Conductivity } \\
(\mathbf{s} / \mathrm{cm})\end{array}$ & $\begin{array}{l}\text { Resistivity } \\
(\mathrm{Ohm} / \mathrm{cm})\end{array}$ \\
\hline $\mathrm{PPy} / \mathrm{rGO}$ & 3.088 & $3.238^{\star} 10^{-1}$ \\
\hline $\mathrm{PPy} / \mathrm{rGO}-\mathrm{aryl}-\mathrm{COOH}$ & 5.394 & $1.854^{\star} 10^{-1}$ \\
\hline
\end{tabular}

Table 4 Sensor sensitivity variation in function of temperature

\begin{tabular}{|ll|}
\hline Temperature & Sensitivity $(\% / \mathrm{ppm})$ \\
\hline 25 & 1.01 \\
\hline 40 & 0.95 \\
\hline 60 & 0.90 \\
\hline 80 & 0.84 \\
\hline
\end{tabular}

Table 5 Impedance parameters were obtained for PPy/rGO and PPy/ rGO-aryl-COOH sensors by fitting data to the equivalent circuit 


\begin{tabular}{|llll|}
\hline & $\mathrm{R}_{\mathrm{c}}(\Omega)$ & $\mathrm{R}_{1}(\Omega)$ & $\mathrm{C}_{1}(\mu \mathrm{F})$ \\
\hline Fresh PPy/rGO & 4.94 & 98.35 & 8.24 \\
\hline $\mathrm{NO}_{2}$ exposed PPy/rGO & 6.79 & 57.34 & 15.32 \\
& & & \\
\hline Fresh Ppy/rGO-aryl-COOH & 5.78 & 109.20 & 6.10 \\
\hline $\mathrm{NO}_{2}$ exposed PPy/ rGO-aryl-COOH & 6.73 & 61.73 & 10.80 \\
\hline
\end{tabular}

Table 6 nitrogen dioxide $\left(\mathrm{NO}_{2}\right)$ sensor based on nanocomposite polypyrrole and functionalized graphene

\begin{tabular}{|c|c|c|c|c|c|c|}
\hline Materials & $\begin{array}{l}\mathrm{NO}_{2} \\
\text { concentration }\end{array}$ & $\begin{array}{l}\text { Work } \\
\text { temperature }\end{array}$ & Sensitivity & $\begin{array}{l}\text { Response } \\
\text { time }\end{array}$ & $\begin{array}{l}\text { Recovery } \\
\text { time }\end{array}$ & Reference \\
\hline rGO & $\begin{array}{l}0.5-20 \mathrm{ppm} \\
\text { (air) }\end{array}$ & RT & - & $2500 \mathrm{~s}$ & - & [48] \\
\hline $\begin{array}{l}\text { PANI thin } \\
\text { film }\end{array}$ & 20 ppm & RT & $\mathrm{Ra} / \mathrm{Rg}$ & 206.19 & - & [49] \\
\hline PPy/ZnO & 100 ppm (air) & RT & $\begin{array}{l}\text { (Ra- } \\
\mathrm{Rg}) / \mathrm{Ra}=38 \%\end{array}$ & $2-4 \min$ & $4 \min$ & [50] \\
\hline $\mathrm{PPy} / \mathrm{rGO}$ & 50 ppm (air) & RT & - & - & - & [51] \\
\hline PEDOT/rGO & 0.5 ppm (air) & RT & - & - & - & [52] \\
\hline PPy/rGO & 2 ppm (air) & RT & $\begin{array}{l}(\mathrm{Ra}- \\
\mathrm{Rg}) / \mathrm{Ra}=22 \\
\%\end{array}$ & $199 \mathrm{~s}$ & $145 \mathrm{~s}$ & our work \\
\hline $\begin{array}{l}\mathrm{PPy} / \mathrm{rGO}- \\
\text { aryl-COOH }\end{array}$ & $2 \mathrm{ppm}$ & RT & $\begin{array}{l}(\mathrm{Ra}- \\
\mathrm{Rg}) / \mathrm{Ra}=30 \\
\%\end{array}$ & $129 \mathrm{~s}$ & $114 \mathrm{~s}$ & our work \\
\hline
\end{tabular}

\section{Figures}




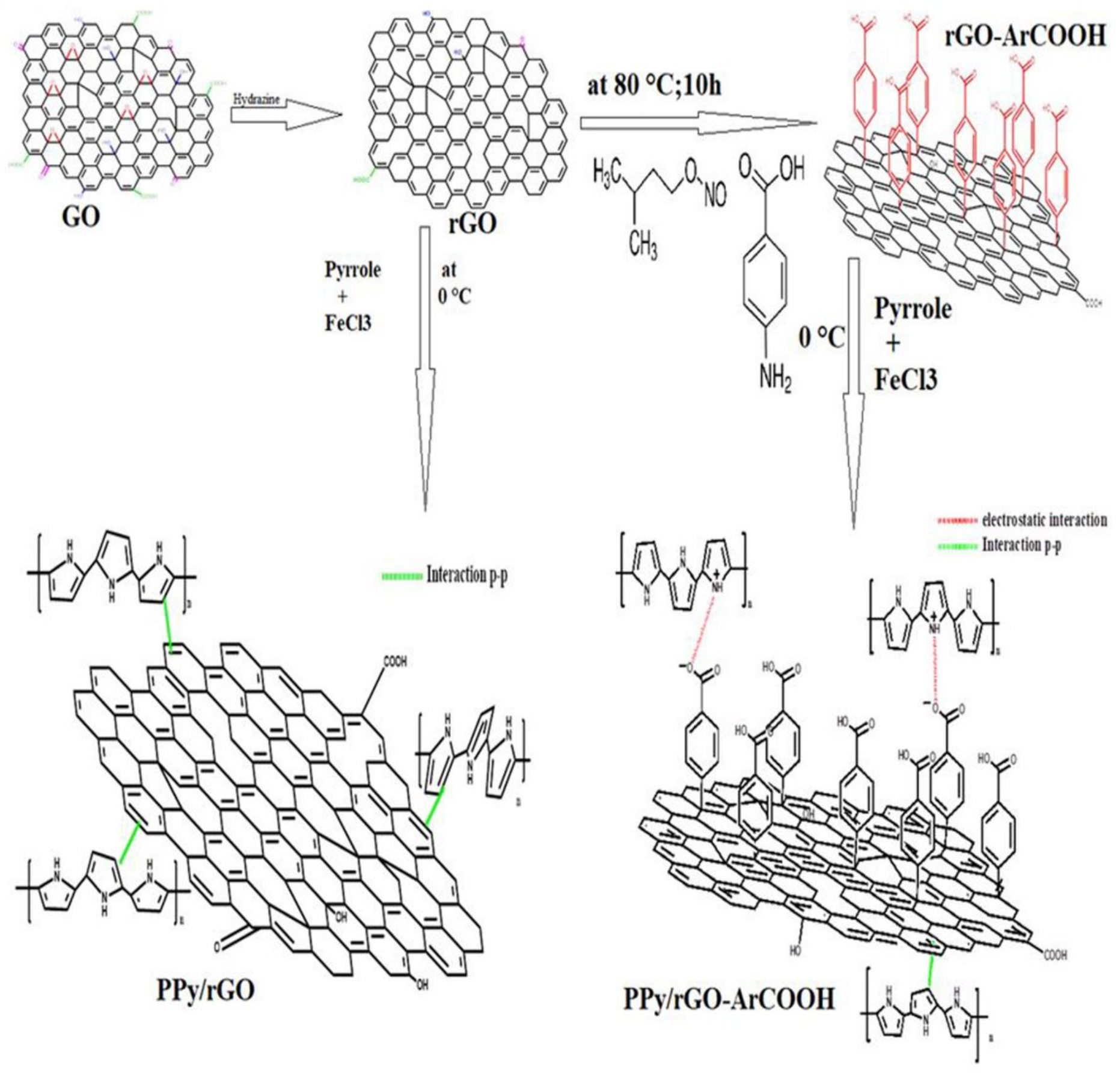

Figure 1

Synthesis steps for growing up polypyrrole on carboxybenzene-functionalized graphene 


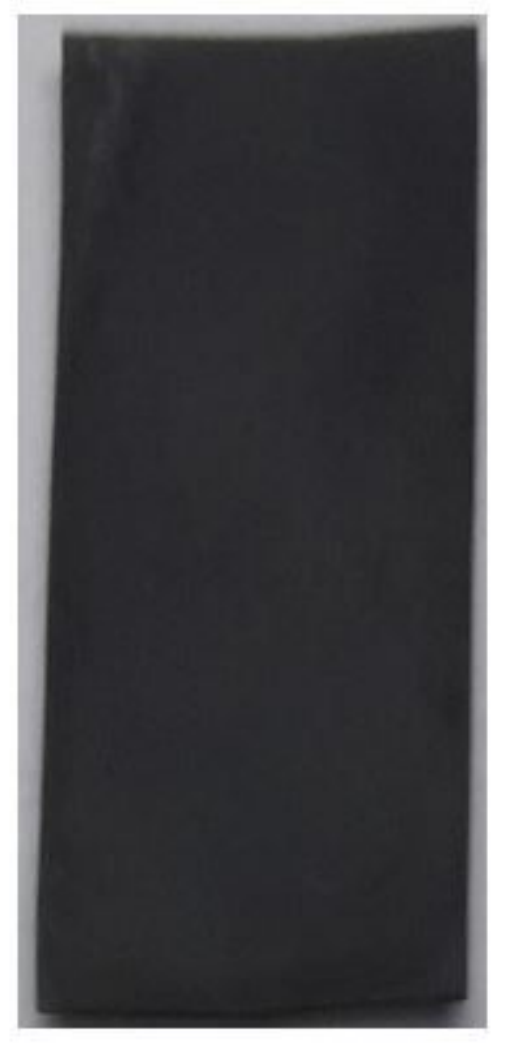

Figure 2

PPy/ rGO-aryl-COOH deposited on BOPET with spin coating 


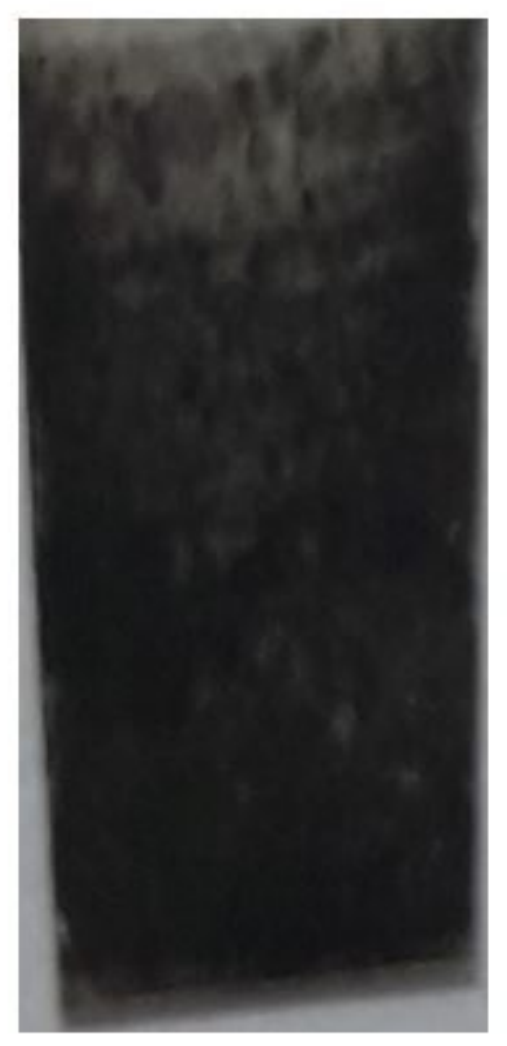

Figure 3

$\mathrm{PPy} / \mathrm{rGO}$ deposited on BOPET with spin coating 


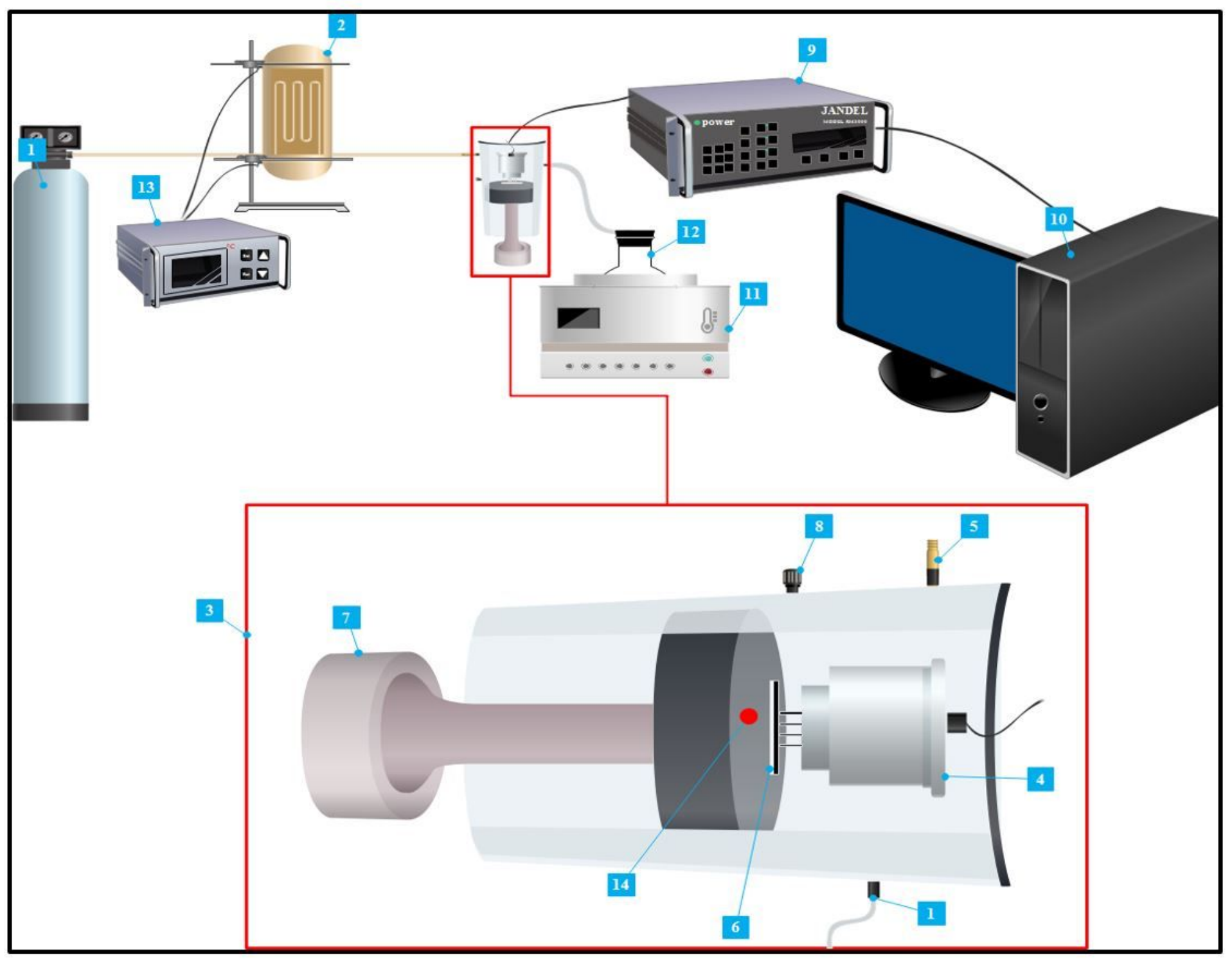

Figure 4

Description of measurement module. 1. Container of nitrogen gas. 2. Heating Element. 3. Test chamber. 4. Measuring head. 5. Cupper canal. 6. Flexible sensitive layer. 7. Piston. 8. Gas vent. 9. Connecting device. 10. Laptop. 11. Heating cap. 12. Boat of water. 13. Temperature controller. 14. Vapor inlet 

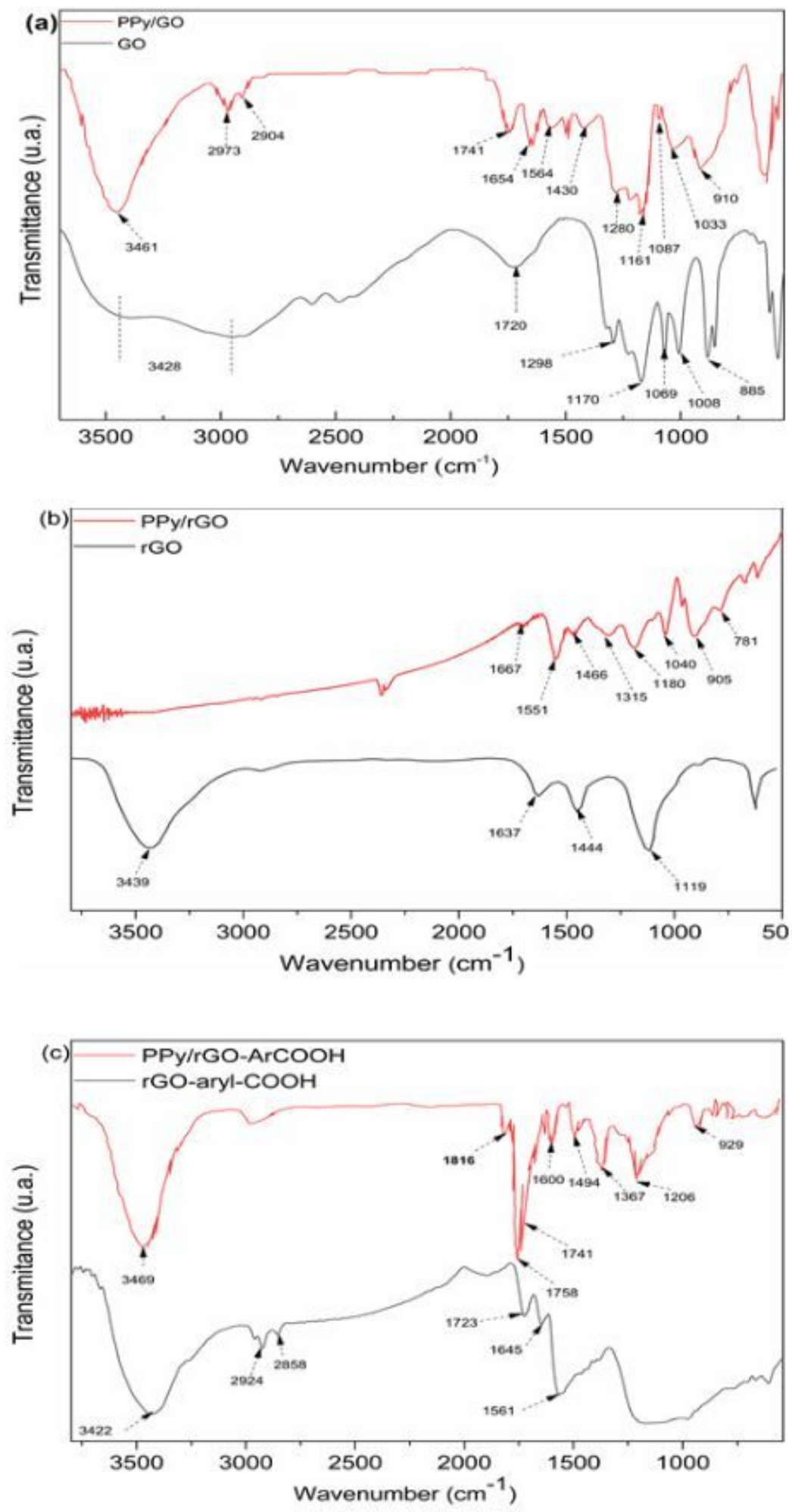

Figure 5

FTIR spectra of graphene and composites 


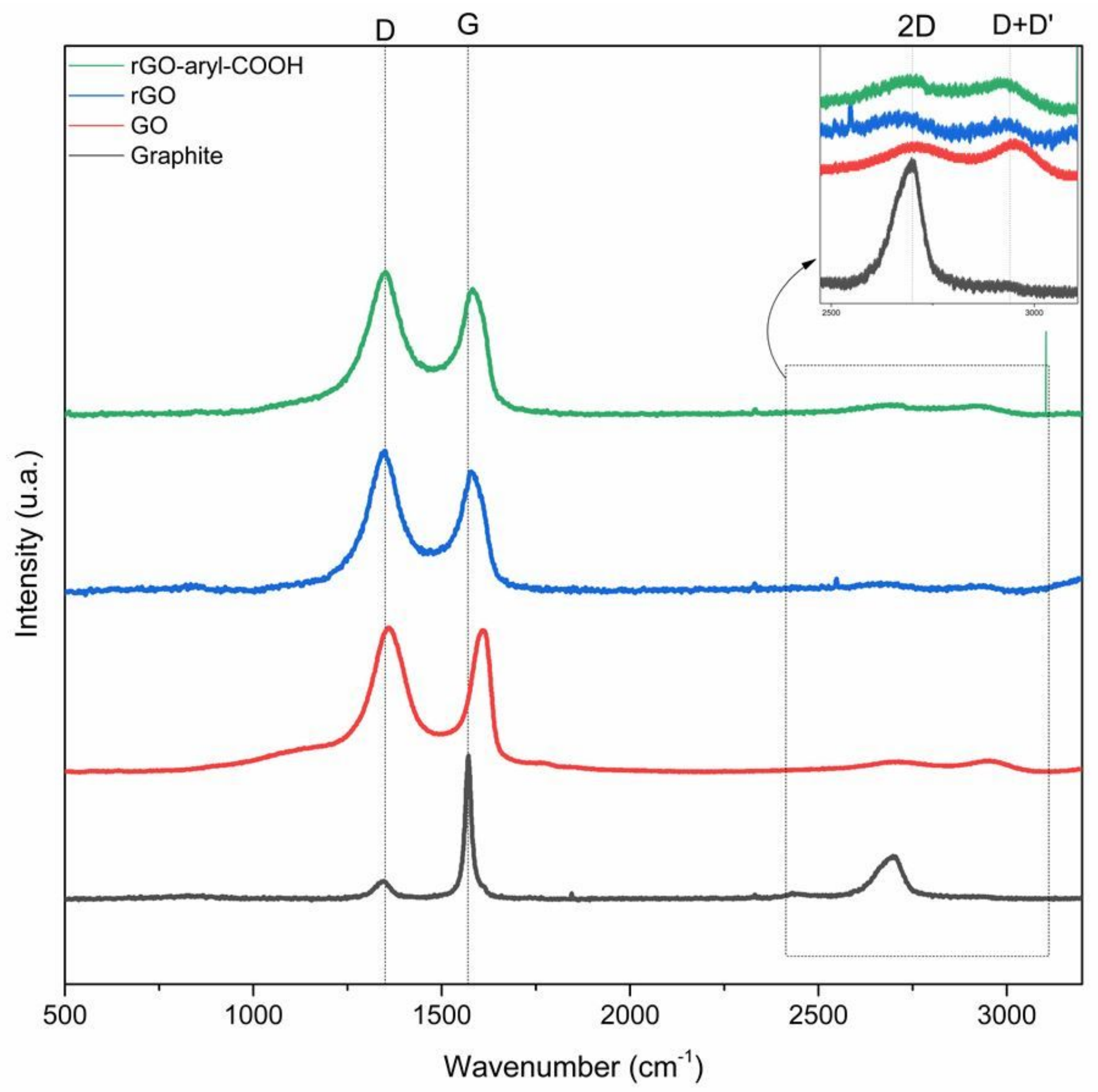

Figure 6

Raman spectra of Graphite, GO, rGO, and rGO-aryl-COOH 


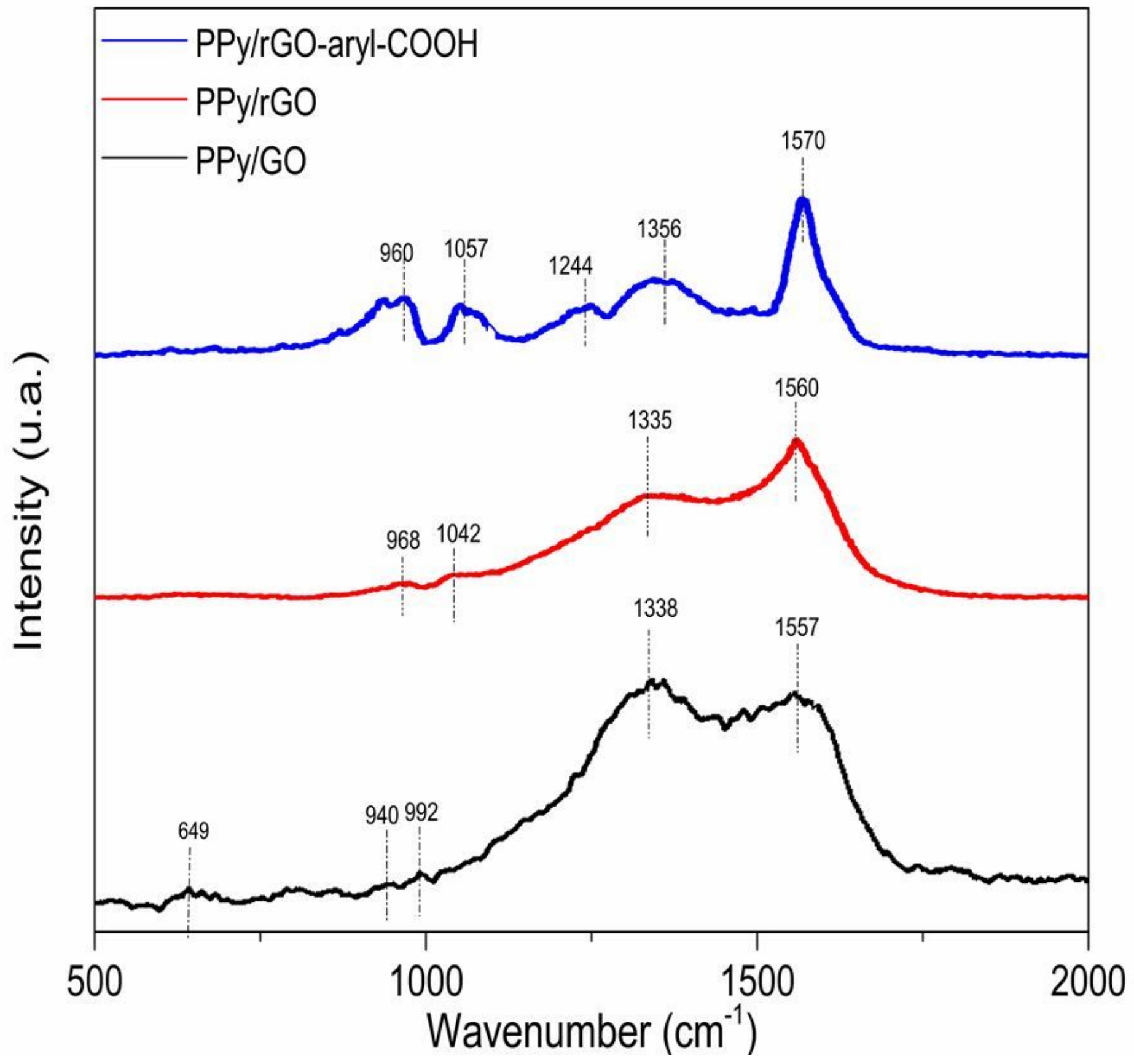

Figure 7

Raman spectra of composites 


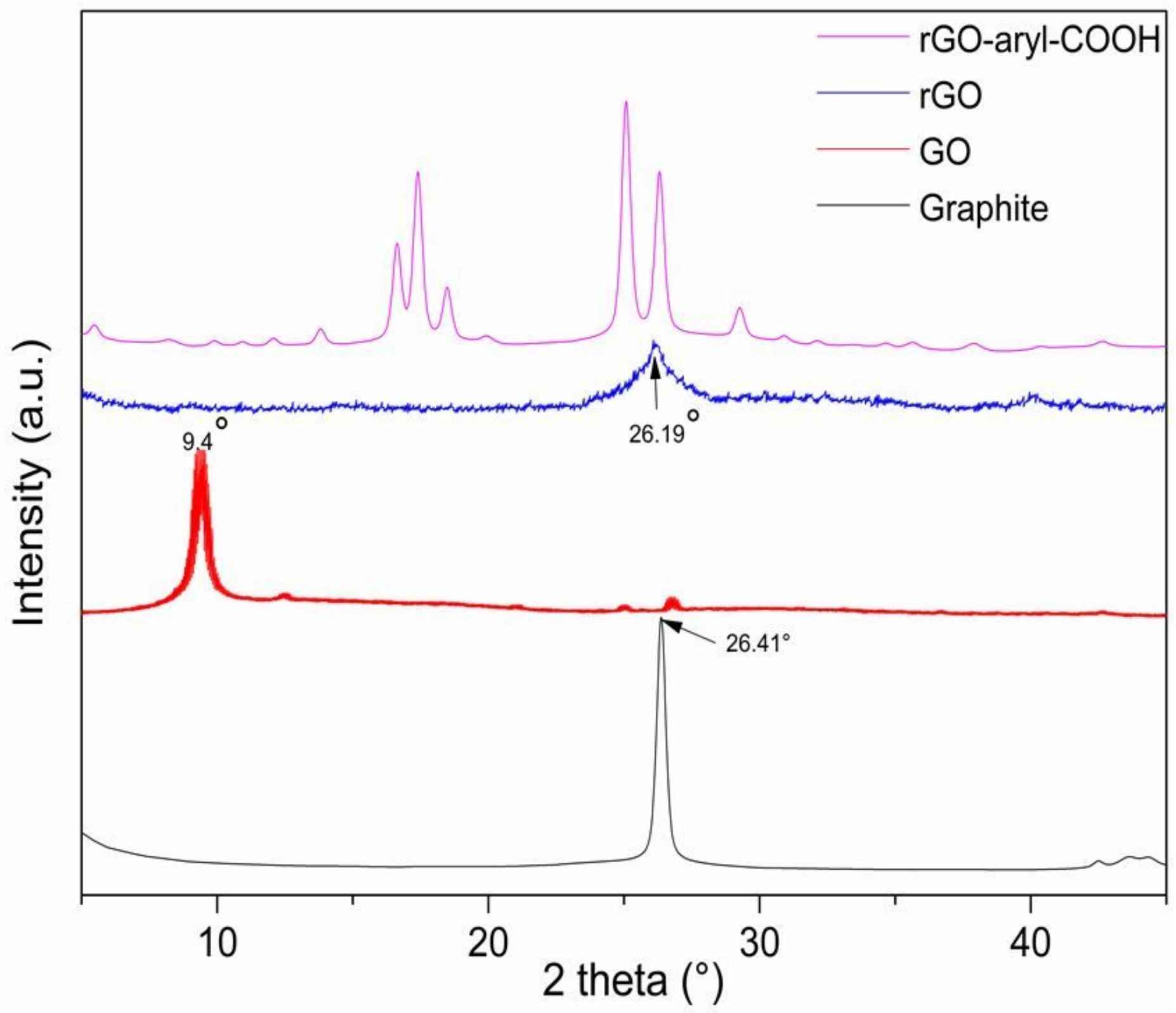

Figure 8

XRD patterns of graphitic materials 


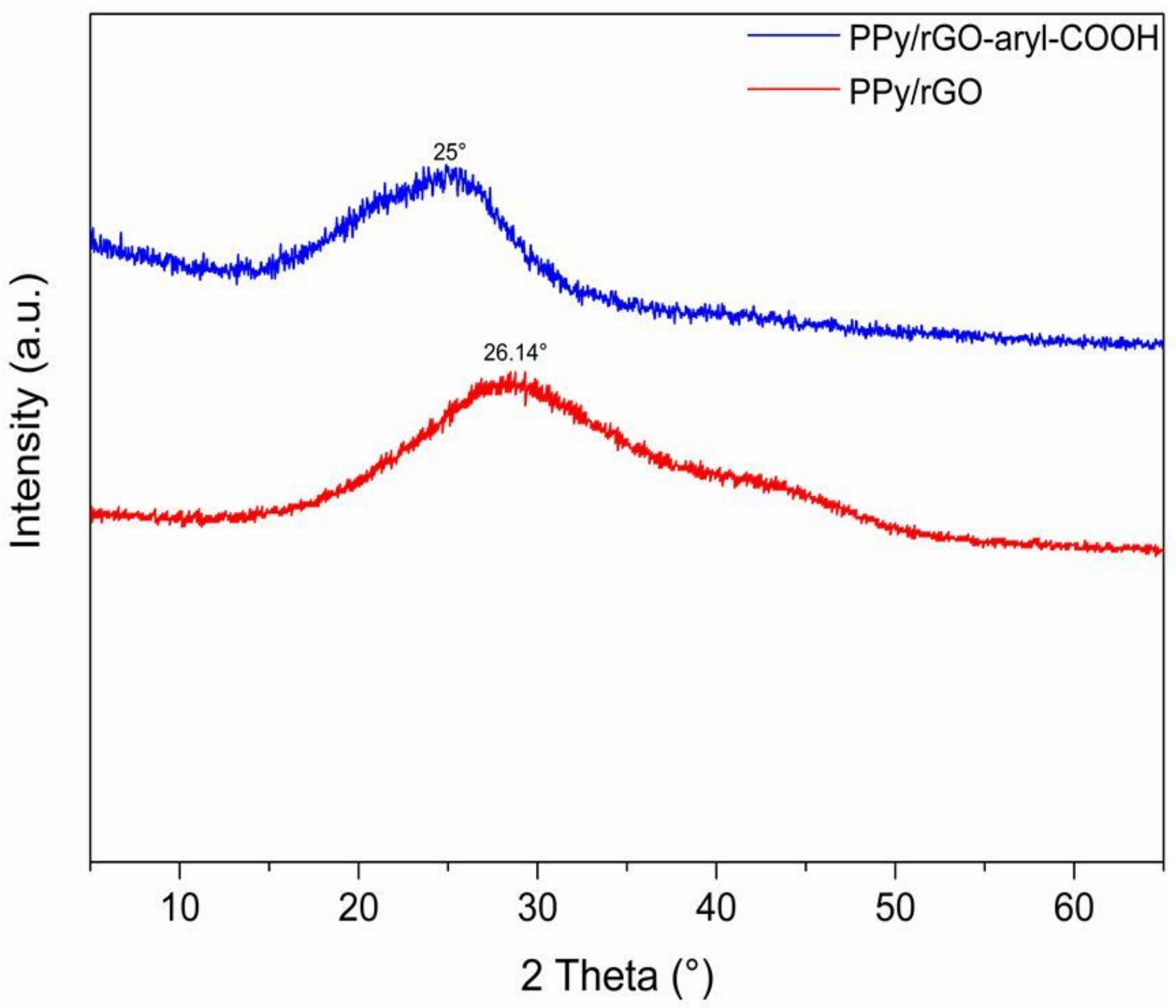

Figure 9

XRD of a PPy/rGO and PPy/rGO-aryl-COOH nanocomposites 

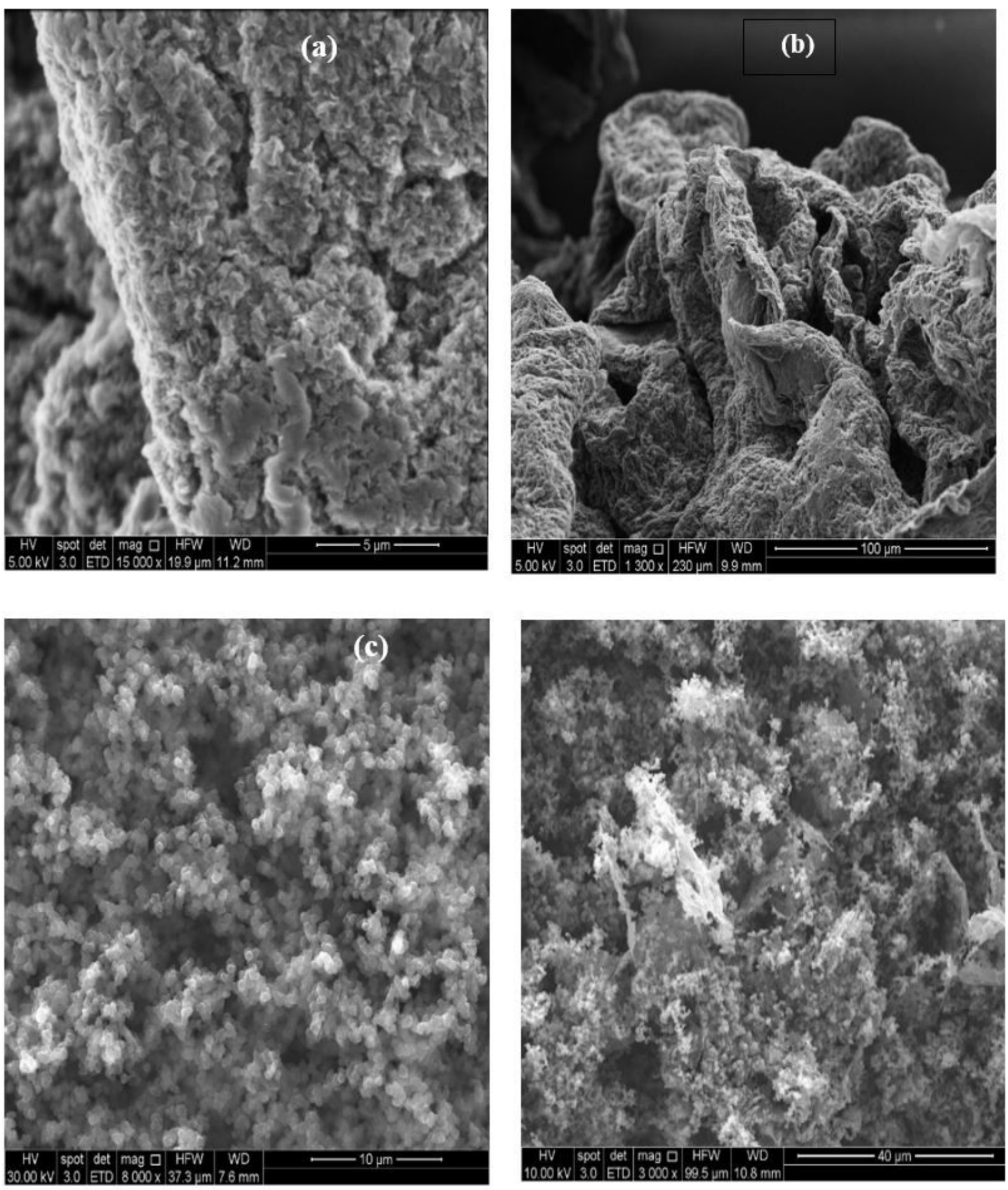

Figure 10

SEM micrographs for (a) rGO, (b) rGO-aryl-COOH, (c) PPy / rGO, (d) PPy / rGO-aryl-COOH 


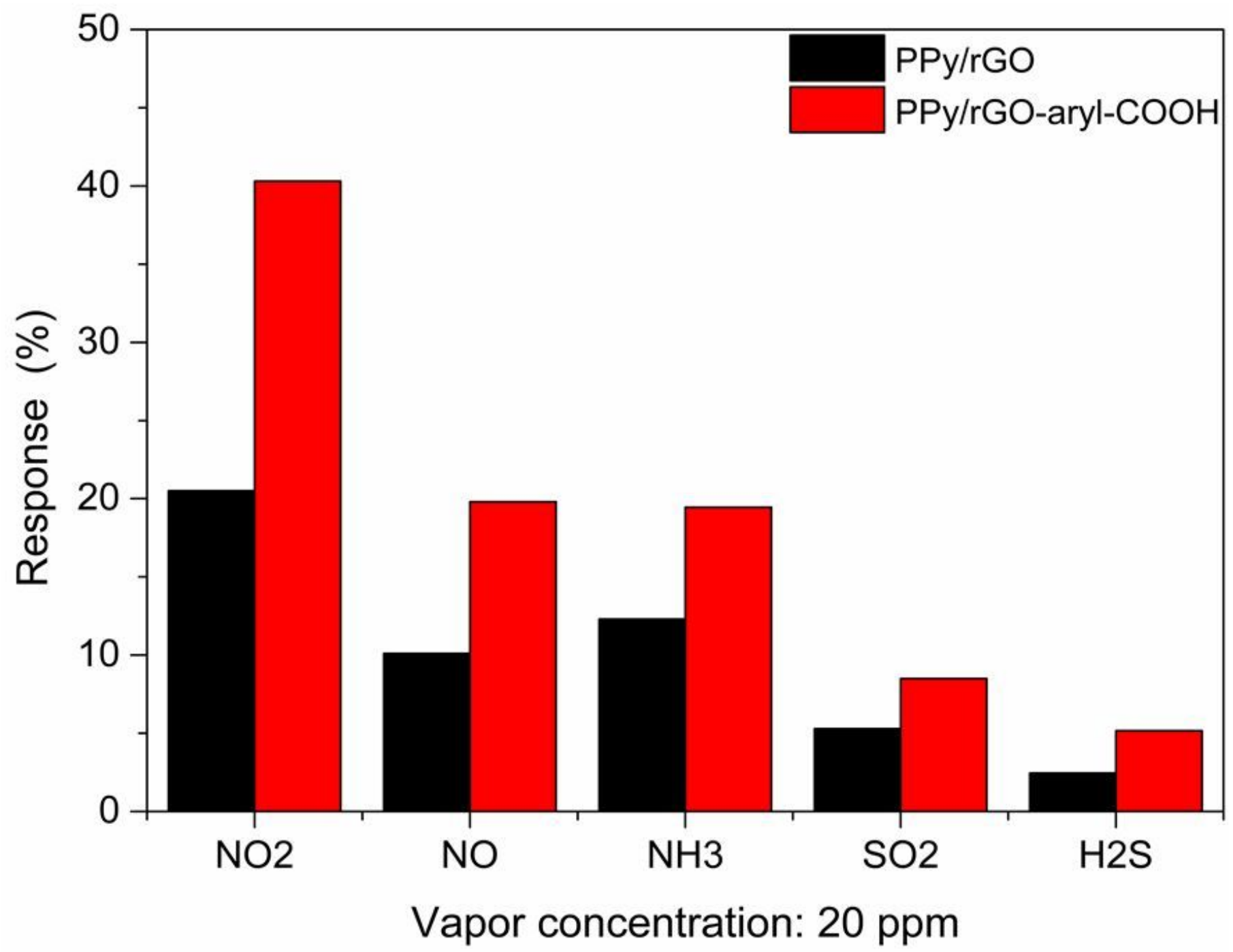

Figure 11

The response of PPy/rGO and PPy/ rGO-aryl-COOH films vis-a-vis gas at a concentration of $20 \mathrm{ppm}$ 


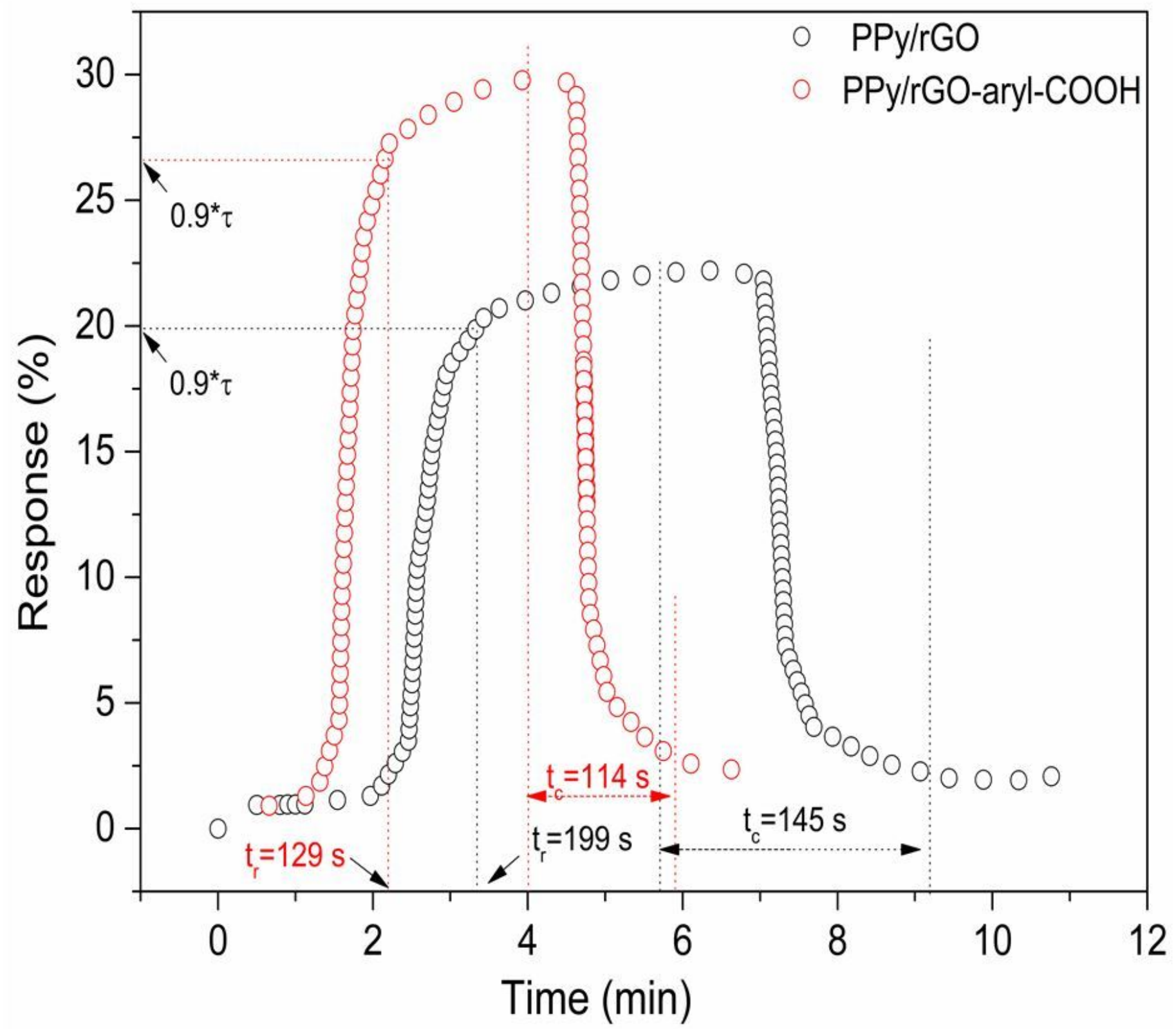

Figure 12

Response rate of 2-ppm NO2 injection on PPy/rGO and PPy/ rGO-aryl-COOH films 


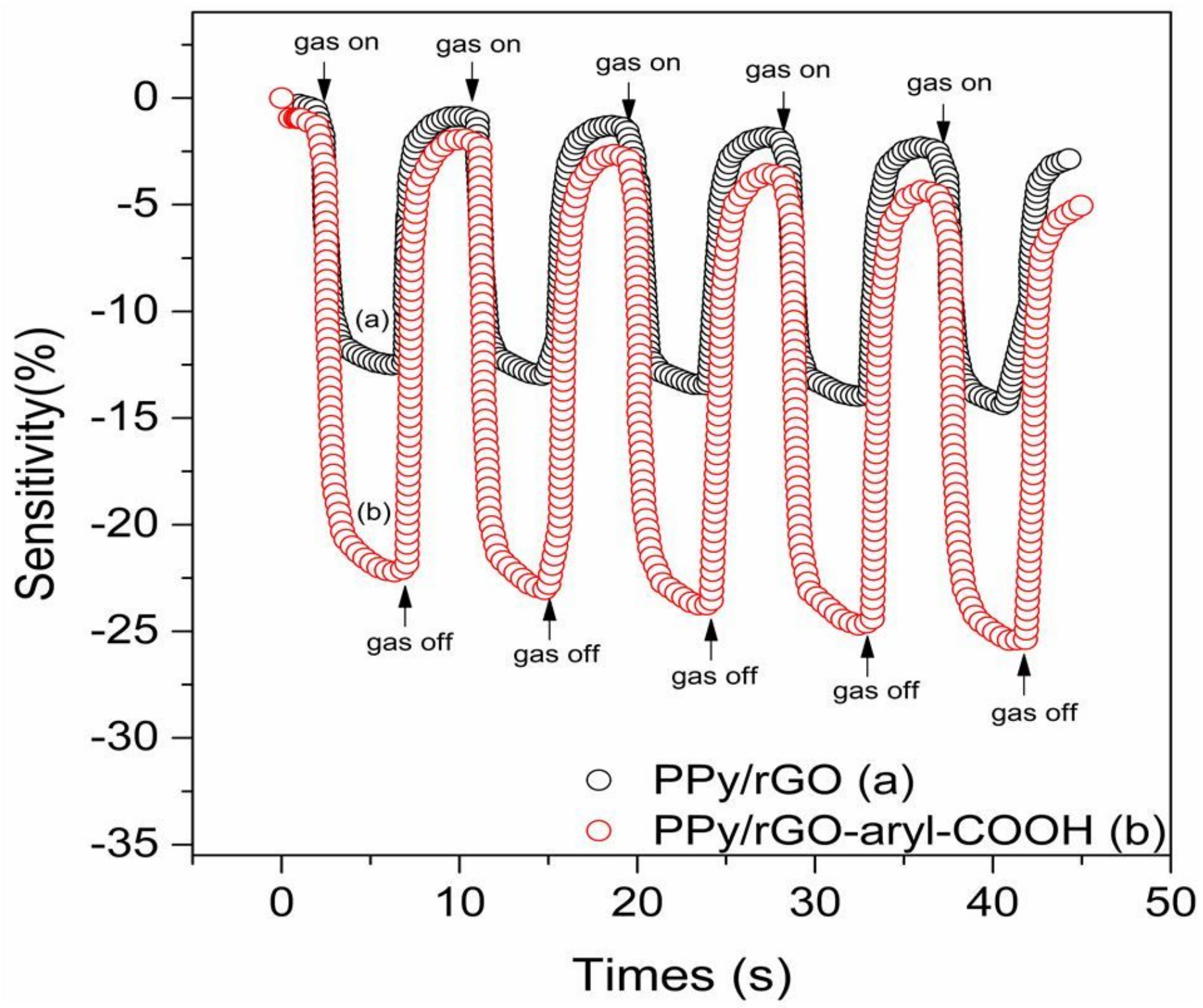

Figure 13

Response reproducibility cycles of nanocomposite toward 2 ppm NO2 (a) PPy/rGO and (b) PPy/rGO-aryl$\mathrm{COOH}$ 


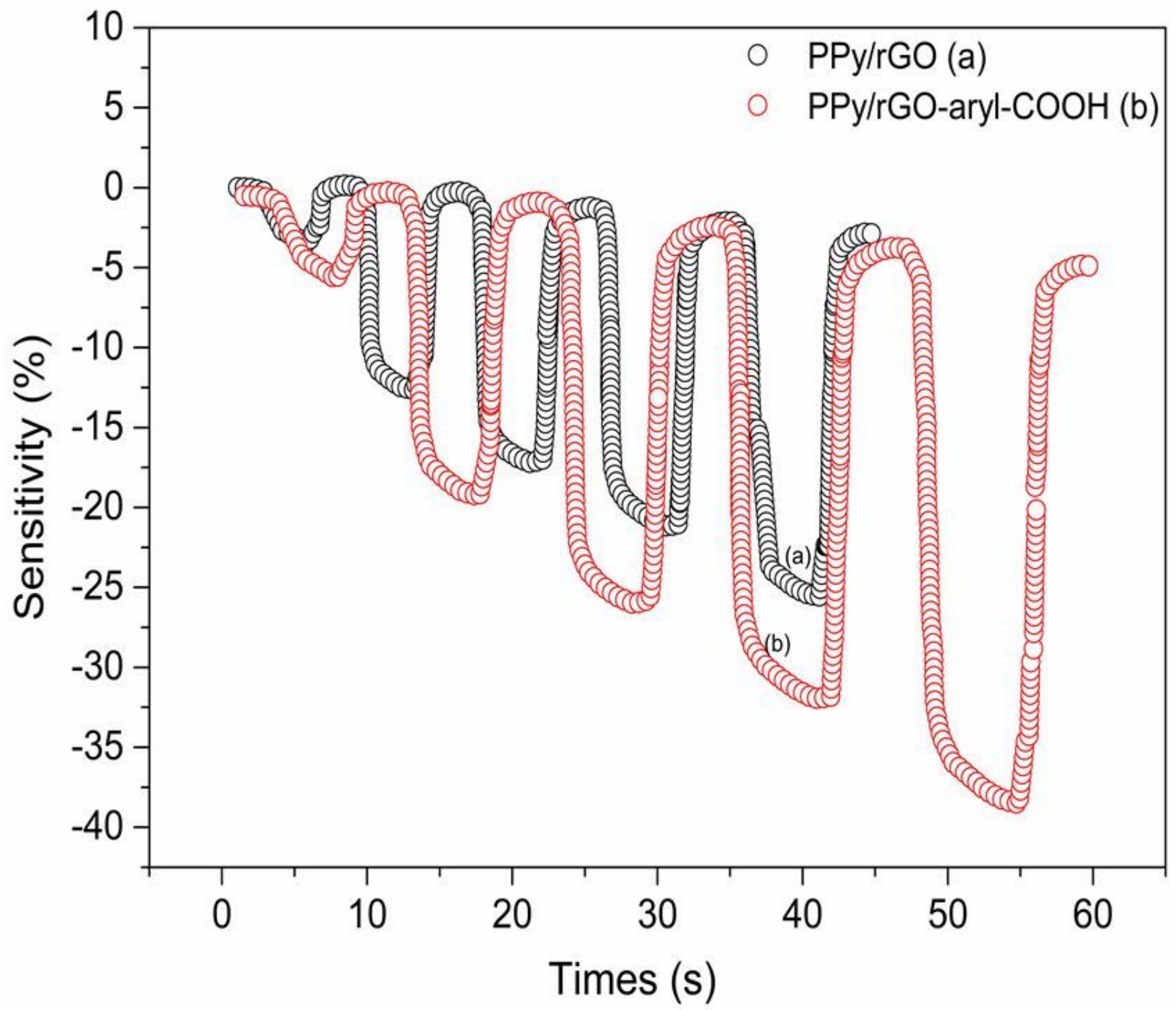

Figure 14

Dynamic response of nanocomposite sensors PPy / rGO (a) and (b) PPy/ rGO-aryl-COOH 


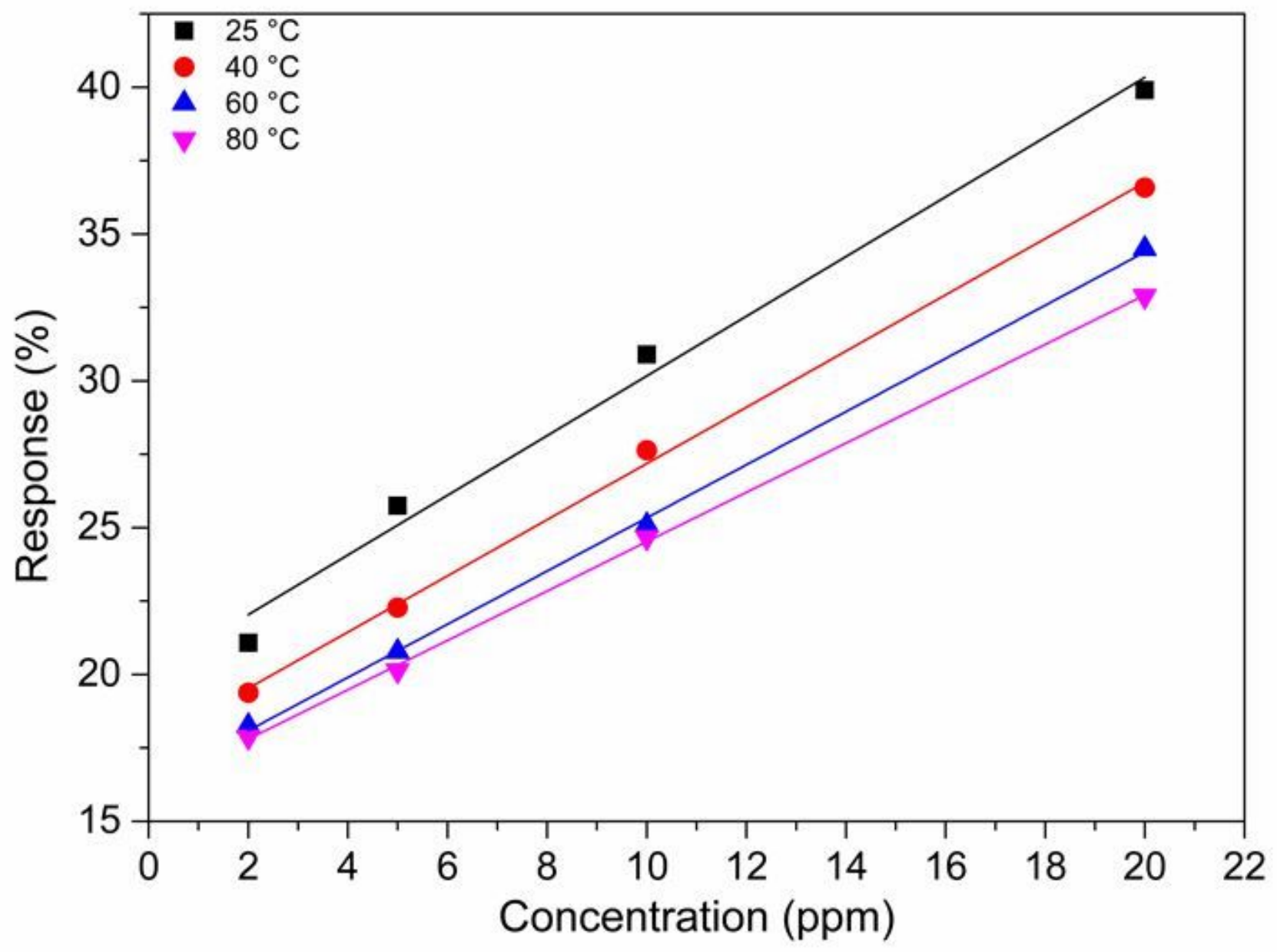

Figure 15

Influence of temperature on the sensor response and sensitivity 


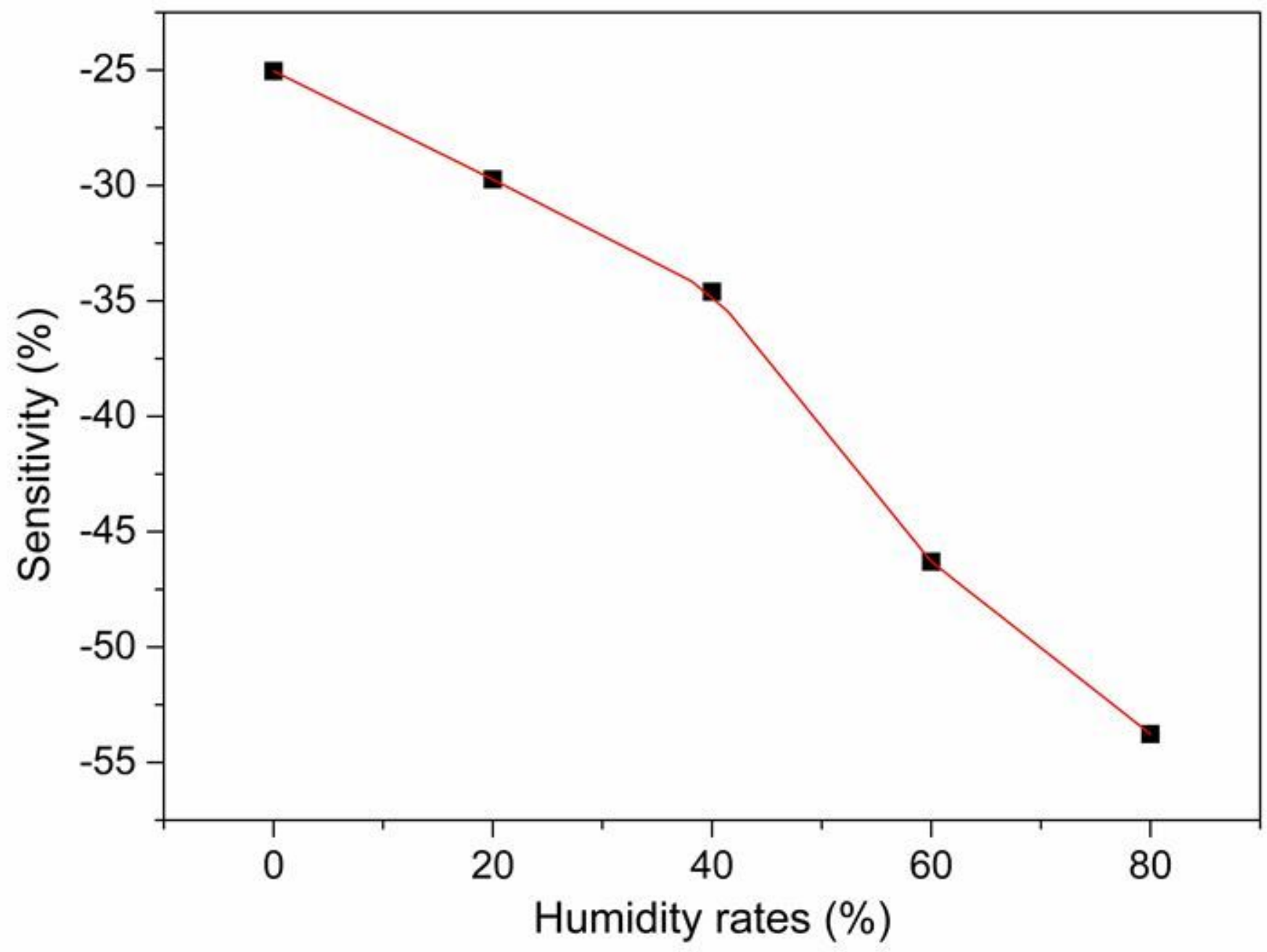

Figure 16

Influence of humidity atmosphere on PPy/ rGO-aryl-COOH responses behavior 

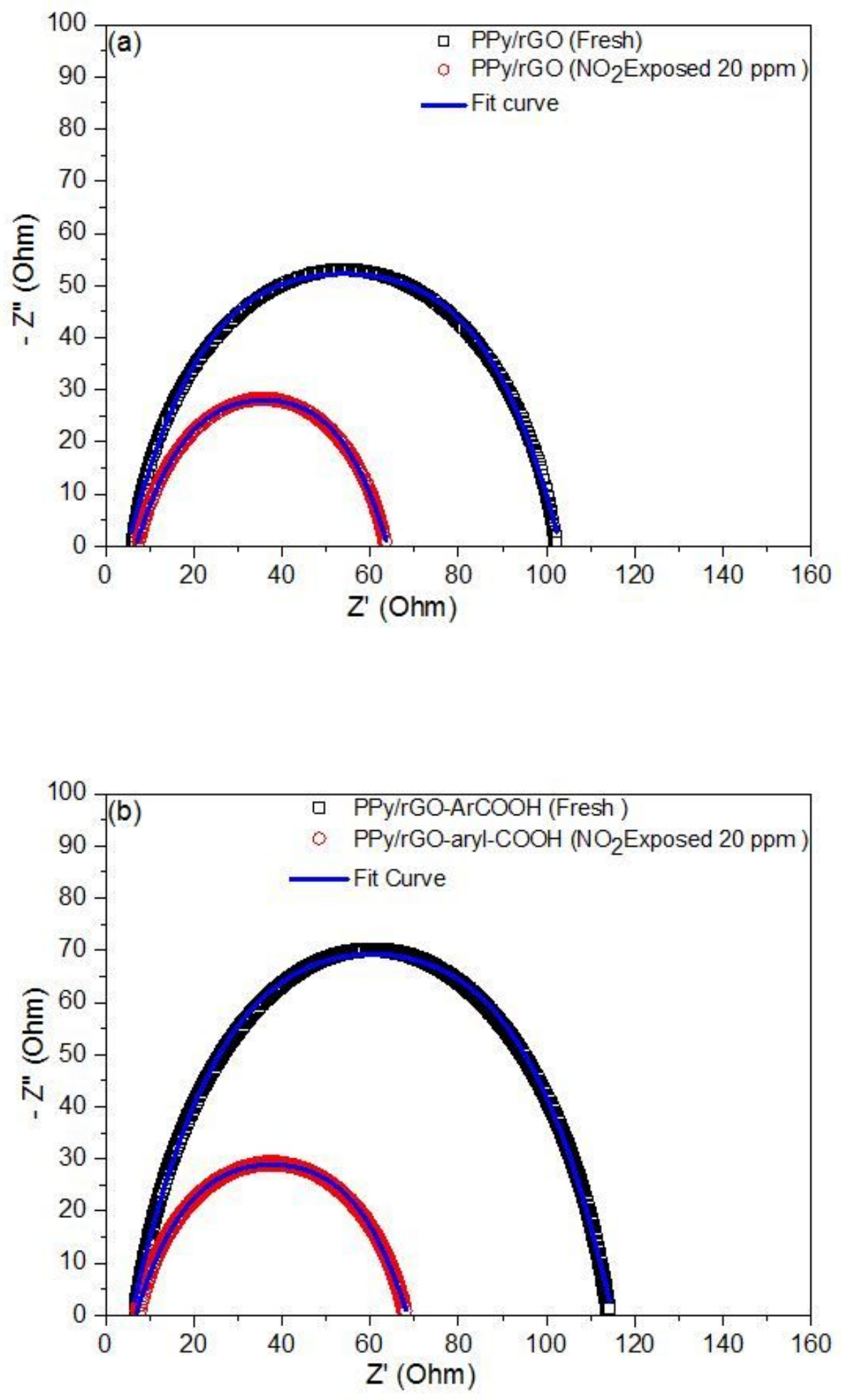

Figure 17

Impedance spectra of PPy/ rGO-aryl-COOH and PPy/rGO under fresh air and $\mathrm{NO} 2$ environment 


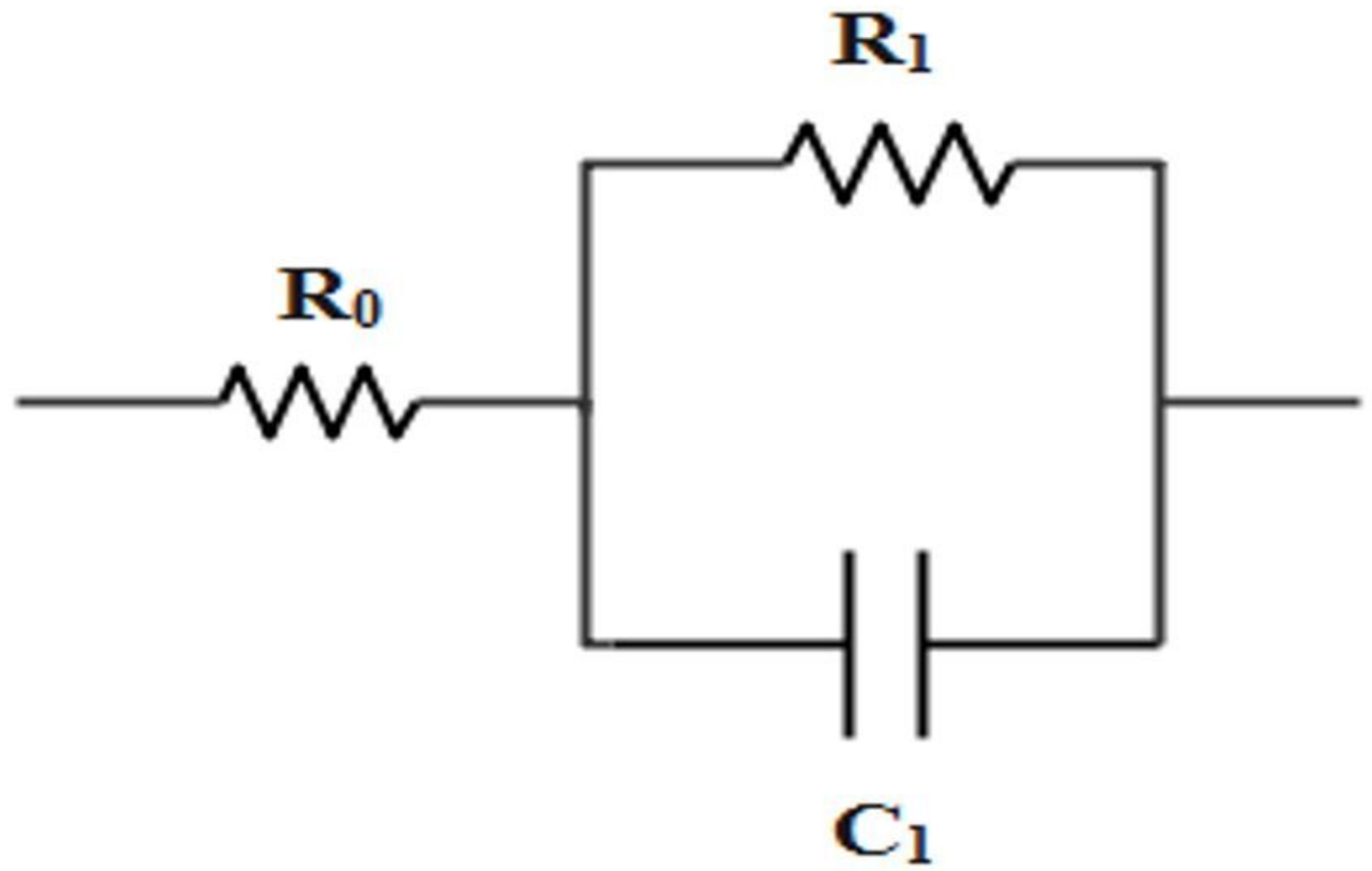

Figure 18

Circuit equivalence 